\title{
Visible Light Responsive Metal Oxide Photoanodes for Photoelectrochemical Water Splitting: a Comprehensive Review on Rational Materials Design
}

\author{
WANG Song-Can, TANG Feng-Qiu, WANG Lian-Zhou \\ (School of Chemical Engineering, The University of Queensland, St Lucia QLD 4072, Australia)
}

\begin{abstract}
Photoelectrochemical (PEC) water splitting provides a "green” approach for hydrogen production. Photoanodes for water oxidation reactions are the bottleneck for PEC water splitting due to the involved thermodynamic and kinetic challenges. To obtain the target of 10\% solar-to-hydrogen (STH) efficiency toward practical applications, efficient photoanodes should be developed. Owing to the intrinsic advantages of low cost, good light harvesting, low toxicity, and excellent (photo)-electrochemical stability, visible light responsive metal oxides such as $\mathrm{WO}_{3}, \alpha-\mathrm{Fe}_{2} \mathrm{O}_{3}$ and $\mathrm{BiVO}_{4}$ have attracted great attention for potential photoanodes and significant achievements have been made in the past decades. In this review, the sate-of-the-art progresses of $\mathrm{WO}_{3}, \alpha-\mathrm{Fe}_{2} \mathrm{O}_{3}$ and $\mathrm{BiVO}_{4}$ photoanodes are summarized with an emphasis on the rational materials design toward efficient PEC water splitting. Moreover, their applications in unassisted PEC water splitting systems are briefly introduced. The perspectives on the challenges and future development of visible light responsive metal oxide photoanodes are presented.
\end{abstract}

Key words: solar energy conversion; semiconductor metal oxides; photoanodes; photoelectrochemical water splitting; solar hydrogen

According to the report of Global Energy and Climate Outlook (GECO) in 2016, the global energy demand and greenhouse gas emissions are expected to grow by $37 \%$ and 30\% between 2010 and 2030, respectively ${ }^{[1]}$. Currently, fossil fuels are still the main energy resources for humanity. In addition to the fact that fossil fuels would be depleted in the near future, the consumption of fossil fuels will boost $\mathrm{CO}_{2}$ emissions, which will exacerbate global warming. Therefore, exploiting other clean and renewable energy resources is significant to address the energy and environmental issues. Solar energy has been regarded as one of the most promising candidates due to its non-emission property and gigantism: approximately $4.3 \times 10^{20} \mathrm{~J}$ of solar energy is transported to the earth in 1 $\mathrm{h}$, which is even larger than the global energy consumption in 1 year (e.g. $4.1 \times 10^{20} \mathrm{~J}$ in $2001^{[2]}$ ). However, it is very challenging to efficiently use solar energy in an economical approach ${ }^{[3]}$.

Photoelectrochemical (PEC) water splitting that uses man-made materials to emulate natural photosynthesis (NP) for solar hydrogen $\left(\mathrm{H}_{2}\right)$ production, providing a potentially economical way to convert solar energy into clean $\mathrm{H}_{2}$ fuel, which has attracted great attention since its first discovery in the $1970 \mathrm{~s}^{[4-8]}$. In the past decades, the PEC water splitting technique has also been derived to other applications such as pollutant degradation ${ }^{[9-12]}, \mathrm{CO}_{2}$ reduction $^{[13-15]}$, and value-added chemical production $^{[16-18]}$. However, the derived applications are beyond the scope of this review, thus we will not discuss in detail. Readers may refer to some excellent recent review articles and book chapters for more information ${ }^{[19-22]}$. Generally, a full PEC cell is composed of a photoanode and a photocathode immerging in an electrolyte solution (Fig. 1). Photoanodes are made of n-type semiconductors, while photocathodes are made of p-type semiconductors. To achieve spontaneous PEC water splitting, the valance band (VB) of the photoanode material should be more positive than the water oxidation potential of $1.23 \mathrm{~V}$ ( $v \mathrm{~s}$

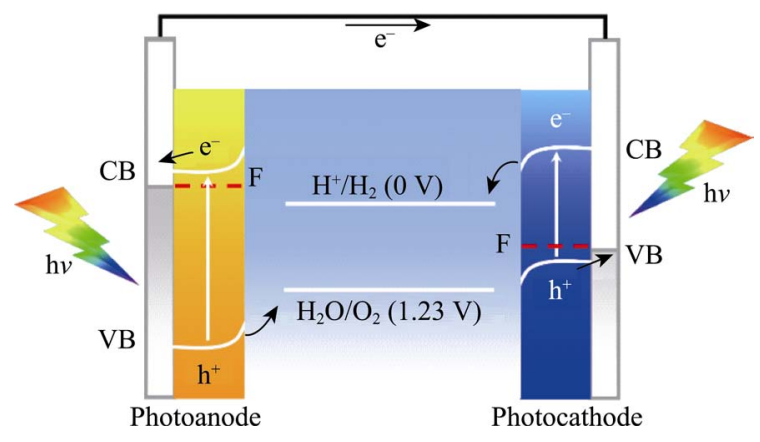

Fig. 1 Schematic illustration of a full PEC cell CB: Conduction Band; VB: Valance Band; F: Fermi Energy Level 
NHE), whereas the conduction band (CB) of the photocathode material should be more negative than the proton reduction potential of $0 \mathrm{~V}$ ( $v s \mathrm{NHE}$ ). Moreover, the band edge positions of the photoanode and photocathode materials should be matched, forming a Z-scheme junction $^{[23]}$. Under light illumination (with energy larger than the bandgaps of the photoelectrode materials), electrons will be excited to the CBs of the photoelectrode materials, leaving holes in the VBs of the photoelectrode materials. Owing to the interior bias generated by the mismatched Fermi levels between the n-type photoanode material and the p-type photocathode material, the electrons from the photoanode will be driven to recombine with the holes in the photocathode through the external circuit, leaving holes in the VB of the photoanode and electrons in the $\mathrm{CB}$ of the photocathode for oxygen evolution reaction (OER) and hydrogen evolution reaction (HER), respectively. In reality, it is very challenging to obtain photoanode and photocathode materials with suitable bandgaps and matchable band edge positions for efficient spontaneous PEC water splitting ${ }^{[24]}$. Fortunately, the researches on photoanodes and photocathodes can be separated by replacing the photocathode or photoanode with a metal counter electrode. An external bias is generally needed to drive the PEC water splitting reactions forward due to the deficient photovoltage generated by only one photoelectrode. In comparison to HER in the photocathode, OER in the photoanode is more challenging because it is an energetically up-hill reaction involving the transfer of four electrons ${ }^{[25]}$. Therefore, the bottleneck for efficient PEC water splitting lies on the photoanode, which has been intensively investigated in the past few decades ${ }^{[26-29]}$.

To achieve efficient photoanodes, adequate light harvesting and efficient charge separation are required. For practical applications, the photoanodes should be low-cost with reasonable durability as well. Considering the above requirements, $\mathrm{TiO}_{2}$ is not a promising candidate due to its large bandgap $\left(\sim 3.2 \mathrm{eV}\right.$ for anatase $\left.\mathrm{TiO}_{2}\right)$ that can only utilize ultraviolet (UV) light, accounting for around $4 \%$ of the solar light spectrum on the earth ${ }^{[30-32]}$. Taking into account that $c a$. $43 \%$ of the solar energy reaching our globe locates in the visible light region, exploring visible light responsive photoanodes is of great significance. During the last four decades, numerous visible light responsive photoanodes have been developed, including metal oxides ${ }^{[33-34]}$, sulphides ${ }^{[35-37]}$, nitrides $^{[38-41]}$, silicon ${ }^{[42]}$, and III-V compounds ${ }^{[43]}$. Although silicon and III-V compounds can generate very high photocurrent densities for PEC water splitting (Fig. 2), they suffer photo-oxidation or photocorrosion and will lose the activity in a very short time. Depositing a

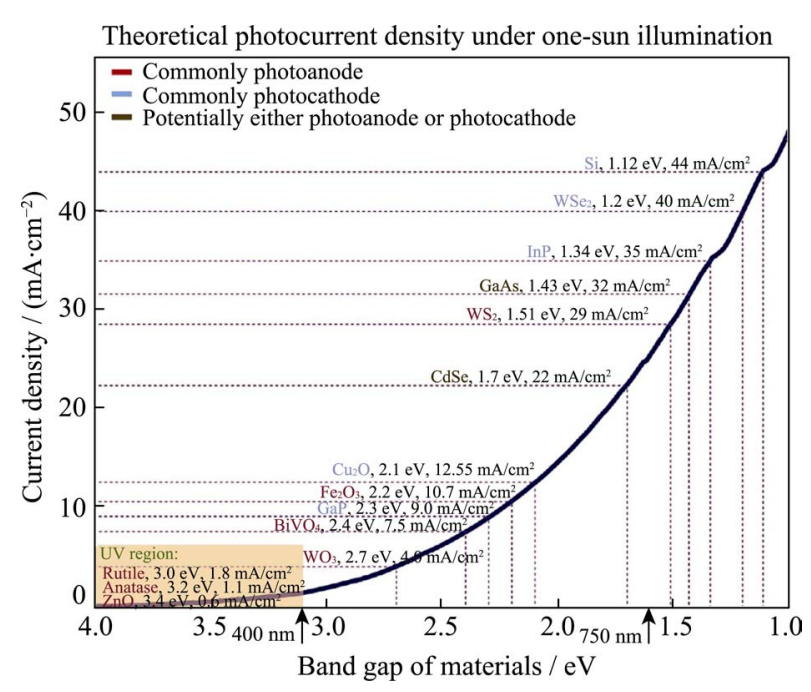

Fig. 2 Theoretical photocurrent densities of several semiconductors under AM 1.5 G illumination

Reproduced with permission from Ref. [45]. Copyright 2013 American Chemical Society

pin-hole free protective layer on the surface of these photoanodes by a high-cost atomic layer deposition (ALD) technique is generally required ${ }^{[44]}$. Moreover, the fabrication of silicon and III-V compounds themselves are prohibitively expensive. Therefore, it is very challenging for the scale-up application of these photoanodes for PEC water splitting. On the other hand, metal sulphides and nitrides are very unstable in aqueous solution under light illumination, and efficient strategies to solve the long-term stability issue are still lacking. By contrast, visible light responsive metal oxide photoanodes may have more opportunities for practical applications due to their low cost and excellent durability in the PEC conditions, which will be the main focus in this review.

Even though metal oxide photoanodes for PEC water splitting have been discussed partly in several review articles in recent years ${ }^{[46-51]}$, due to the dynamic development of this research field, a comprehensive review focused on the rational design of visible light responsive metal oxide photoanodes is still necessary to provide readers with a better understanding of the state-of-the-art progress in this dynamic research field. This review article will introduce the state-of-the-art development of efficient visible light responsive metal oxide photoanodes for PEC water splitting. In particular, $\mathrm{WO}_{3}$, $\alpha-\mathrm{Fe}_{2} \mathrm{O}_{3}$, and $\mathrm{BiVO}_{4}$ photoanodes are the hot photoanode materials under research, which will be mainly discussed with an emphasis on the materials design toward efficient water splitting. In addition, the applications of visible light responsive metal oxide photoanodes in unassisted water splitting will be concisely introduced. Finally, this review will close with a brief summary of the current research status and challenges, along with the perspec- 
tives of visible light responsive metal oxide photoanodes for PEC water splitting. We hope to shed light on the further development of low-cost and efficient photoanodes for solar fuel production.

\section{Development of efficient photoanodes}

Visible light responsive metal oxide photoanodes have attracted great attention due to their intrinsic advantages such as low cost and relatively good photostability in aqueous solution in a certain $\mathrm{pH}$ range. However, the $\mathrm{CB}$ position of most metal oxides is more positive than the proton reduction potential. Thus, external bias is required to achieve PEC water splitting. In this section, the properties and the state-of-the-art progresses of $\mathrm{WO}_{3}, \alpha-\mathrm{Fe}_{2} \mathrm{O}_{3}$, and $\mathrm{BiVO}_{4}$ photoanodes will be discussed in detail.

\section{$1.1 \mathrm{WO}_{3}$ photoanodes}

With a bandgap of 2.5-2.8 eV, $\mathrm{WO}_{3}$ can absorb sunlight with the wavelength up to $c a .500 \mathrm{~nm}$, which equals to a theoretical solar-to-hydrogen (STH) efficiency of $6 \%{ }^{[52]}$. Furthermore, $\mathrm{WO}_{3}$ possesses some good properties such as moderate hole diffusion length $(\sim 150 \mathrm{~nm})$, good electron mobility $\left(\sim 12 \mathrm{~cm}^{2} /(\mathrm{V} \cdot \mathrm{s})\right)$ and excellent stability against photocorrosion in acidic electrolyte, which make it a good candidate as photoanodes for PEC water splitting ${ }^{[53]}$. However, severe bulk charge recombination and poor stability in the solution with a $\mathrm{pH}>4$ are the main drawbacks for $\mathrm{WO}_{3}$ photoanodes ${ }^{[54]}$.

Modifying the surface of $\mathrm{WO}_{3}$ films with oxygen evolution cocatalysts (OECs) can improve not only the surface kinetics but also the stability. By depositing a thick cobalt-based (Co-Pi) OEC ( $>1.5 \mu \mathrm{m})$ on $\mathrm{WO}_{3}$ photoanodes, all photogenerated holes were used for $\mathrm{O}_{2}$ evolution and the formation of peroxide species was completely suppressed, resulting in good long-term stability (Fig. 3$)^{[55]}$. The interfacial states generated in the $\mathrm{WO}_{3} / \mathrm{Co}-\mathrm{Pi}$ junction will shift the flat band potential negatively when occupied while shift the flat band potential positively when emptied. Consequently, $\mathrm{WO}_{3} / \mathrm{Co}-\mathrm{Pi}$ photoanode suffers less charge recombination when its Fermi level is above the interfacial states. However, more charge recombination occurs when its Fermi level is below the interfacial states. Other OECs such as $\mathrm{FeOOH}^{[56]}, \mathrm{CoO}_{x}{ }^{[57]}$, and $\mathrm{Mn}$ based catalyst ${ }^{[58]}$ have also been reported for modifying $\mathrm{WO}_{3}$ photoanodes. On the other hand, modifying the surface of $\mathrm{WO}_{3}$ films with a passivation layer (e.g. $\left.\mathrm{HfO}_{2}\right)$ is also effective to reduce the charge recombination and improve the lifetime of electrons, resulting in enhanced photocurrent densities ${ }^{[59]}$.

Nanostructural modification can effectively shorten

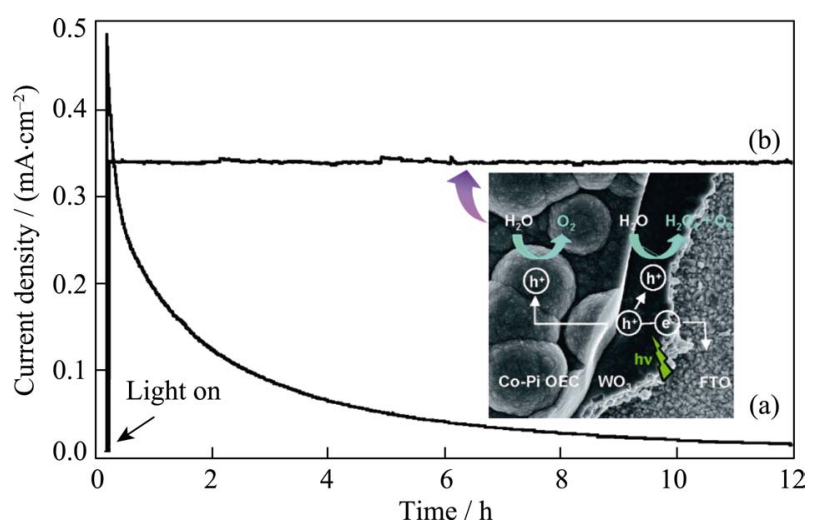

Fig. 3 I- $t$ curves of a bare $\mathrm{WO}_{3}$ photoanode (a) and a Co-Pi modified $\mathrm{WO}_{3}$ photoanode (b)

Inset: SEM image demonstrating charge transfer and separation between the Co-Pi layer, $\mathrm{WO}_{3}$, and FTO substrate

Reproduced with permission from Ref. [55]. Copyright 2011 American Chemical Society

the migration distance of photogenerated charge carriers, thereby improving the charge separation efficiency in the bulk, resulting in enhanced PEC performance. Vertically aligned $\mathrm{WO}_{3}$ nanowire arrays were grown on fluorine doped tin oxide (FTO) substrates by a seed-assisted solvothermal method (Fig. 4(a)) ${ }^{[60]}$. By adjusting the precursors in the solution, nanoflake array films with different thicknesses were also achieved (Fig. 4(b) and 4(c)). Interestingly, the nanoflakes exhibit lower band gap values than the nanowires. The nanoflake film with a film thickness of $5.6 \mu \mathrm{m}$ shows the highest saturation photocurrent density under AM 1.5G illumination (Fig. 4(d)). A simultaneous etching and reducing method was applied to generate pores and oxygen vacancies on the pre-grown $\mathrm{WO}_{3}$ nanoflakes, which increases the surface reaction sites and the charge carrier densities, resulting in enhanced PEC performance ${ }^{[61]}$. Similarly, etching $\mathrm{WO}_{3}$ nanoplate photoanodes also exhibited higher photocatalytic activity for both PEC water splitting and methylene blue (MB) degradation ${ }^{[62]}$. Most of the nanostructural $\mathrm{WO}_{3}$ films are grown on FTO substrates via a seed- assisted solvothermal or hydrothermal method. However, numerous grain boundaries in the seed layer may serve as charge recombination centers, reducing the PEC performance ${ }^{[63]}$. Thus, directly growing $\mathrm{WO}_{3}$ nanostructures on bare FTO substrates may achieve higher photocurrent densities. A seed-free hydrothermal method was developed to grow $\mathrm{WO}_{3}$ nanoplate arrays vertically on FTO substrates, which exhibits a high photocurrent density of $4.13 \mathrm{~mA} / \mathrm{cm}^{2}$ at $1.6 \mathrm{~V}$ (vs Ag/AgCl) under illumination of a $500 \mathrm{~W}$ Xe lamp in $0.5 \mathrm{~mol} / \mathrm{L} \mathrm{H}_{2} \mathrm{SO}_{4}$ electrolyte ${ }^{[64]}$. In addition, directly growing $\mathrm{WO}_{3}$ nanorods on FTO substrates also show enhanced photocurrent denstities ${ }^{[65]}$. Other $\mathrm{WO}_{3}$ nanostructures such as porous nanorod arrays ${ }^{[66]}$, 

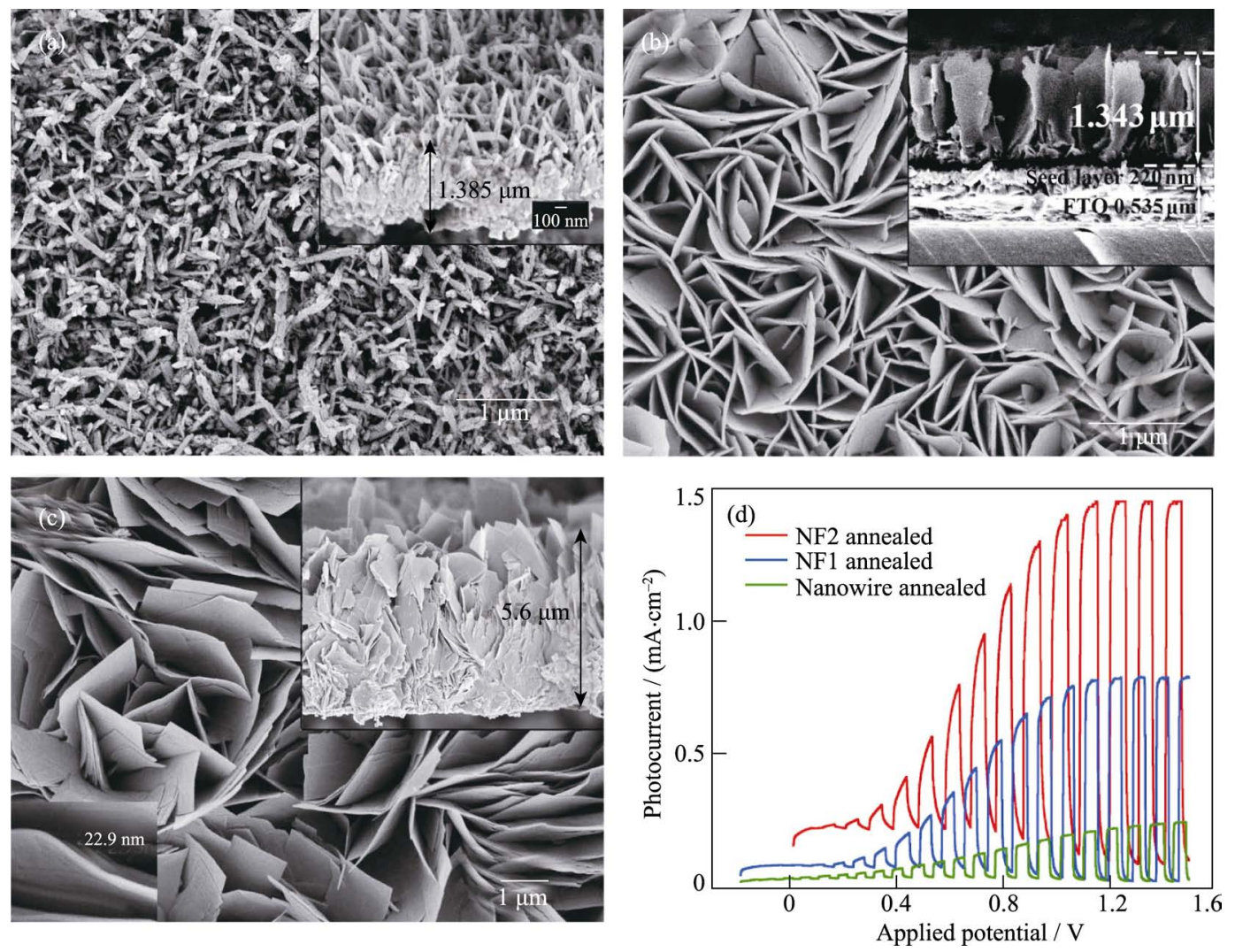

Fig. 4 FESEM images of the as-prepared $\mathrm{WO}_{3}$ films

(a) Nanowires; (b) Nanoflakes-1 (NF1); (c) Nanoflakes-2 (NF2) Insets: film cross section; (d) Photocurrent density vs applied potential curves Reproduced with permission from Ref. [60]. Copyright 2011 American Chemical Society

hexagonal nanoflowers ${ }^{[67]}$, nanoneedles ${ }^{[68]}$, and hierarchical architectures ${ }^{[69]}$ have also been reported.

Theoretical calculations have confirmed that $\{002\}$ is the most reactive facets for $\mathrm{WO}_{3}{ }^{[70]}$. Thus, tailoring the exposure of $\{002\}$ is another strategy to enhance the PEC performance of $\mathrm{WO}_{3}$ photoanodes. For example, a $\mathrm{WO}_{3}$ photoanode with exposed $\{002\}$ facets shows a photocurrent density over twice higher than the counterpart with randomly oriented facets ${ }^{[71]}$. In addition to crystal facet orientation, the morphology also synergistically affect the PEC performance, which has been confirmed by comparing the PEC performance of $\mathrm{WO}_{3}$ nano-multilayers with highly exposed $\{002\}$ facets (60\%) and $\mathrm{WO}_{3}$ nanorods with less exposed $\{002\}$ facets $(20 \%)^{[72]}$. Owing to the unique multilayered nanostructure and the preferential exposure of highly reactive $\{002\}$ facets, the $\mathrm{WO}_{3}$ nano-multilayers exhibit higher photocurrent densities. Recently, a breakthrough of PEC performance was achieved by $\mathrm{WO}_{3}$ nanoplate arrays with dominant $\{002\}$ facets ${ }^{[73]}$. The $\{002\}$ facet oriented $\mathrm{WO}_{3}$ films were synthesized by a hydrothermal process with oxalic acid as the capping agent. Interestingly, elongating the hydrothermal reaction time caused the conversion of $\{002\}$ facets to $\{200\}$ facets (Fig. 5(a)). With the same film thickness, the $\mathrm{WO}_{3}$ photoanode with exposed $\{002\}$ facets exhibit a much higher photocurrent density than that of the counterpart with exposed $\{200\}$ facets. Moreover, the $\mathrm{WO}_{3}$ photoanode with exposed $\{002\}$ facets obtained via a two-step hydrothermal method exhibits an extraordinary photocurrent density of $3.7 \mathrm{~mA} / \mathrm{cm}^{2}$ at $1.23 \mathrm{~V}$ (vs RHE) without any OECs or sacrificial agent (Fig. 5(b)). DFT calculations reveal that the complete water oxidation reaction is easier to take place on $\{002\}$ facets compared to $\{200\}$ facets. The intermediate product of hydroxyl group tends to accumulate on $\{200\}$ facets due to the higher energy barrier for water oxidation. As a result, the photostability of $\{200\}$ facets is much poorer than that of $\{002\}$ facets (Fig. 5(c)).

Doping is an efficient strategy to change the conductivity and electronic structures of a semiconductor, which can tailor the charge transport and light harvesting. Generally, anion doping can reduce the bandgap of $\mathrm{WO}_{3}$ by shifting the VB upward, which is attributable to the hybrid of the $p$ states of the doped anion with the O2p states ${ }^{[74]}$. A carbon doped $\mathrm{WO}_{3}$ photoanode exhibited around 50\% enhanced photocurrent densities compared to the undoped attributed under visible light illumination, which is attributed to the reduced bandgap that can absorb more visible light ${ }^{[75]}$. Surprisingly, the bandgap of $\mathrm{WO}_{3}$ can be significantly reduced from 2.6 to $1.9 \mathrm{eV}$ by incorporating $\mathrm{N}_{2}$ into the $\mathrm{WO}_{3}$ crystal structure to form an extraordinary thermal stable compound of $x \mathrm{~N}_{2} \cdot \mathrm{WO}_{3}$ 


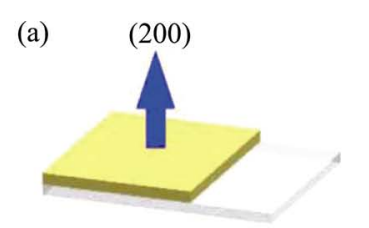

1 -step-16 h

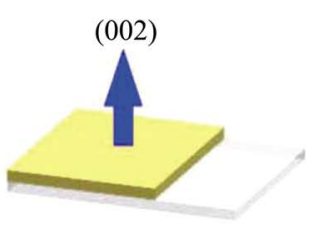

1-step-8 h

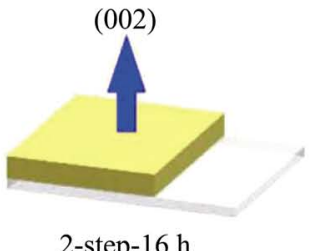

2-step-16 h
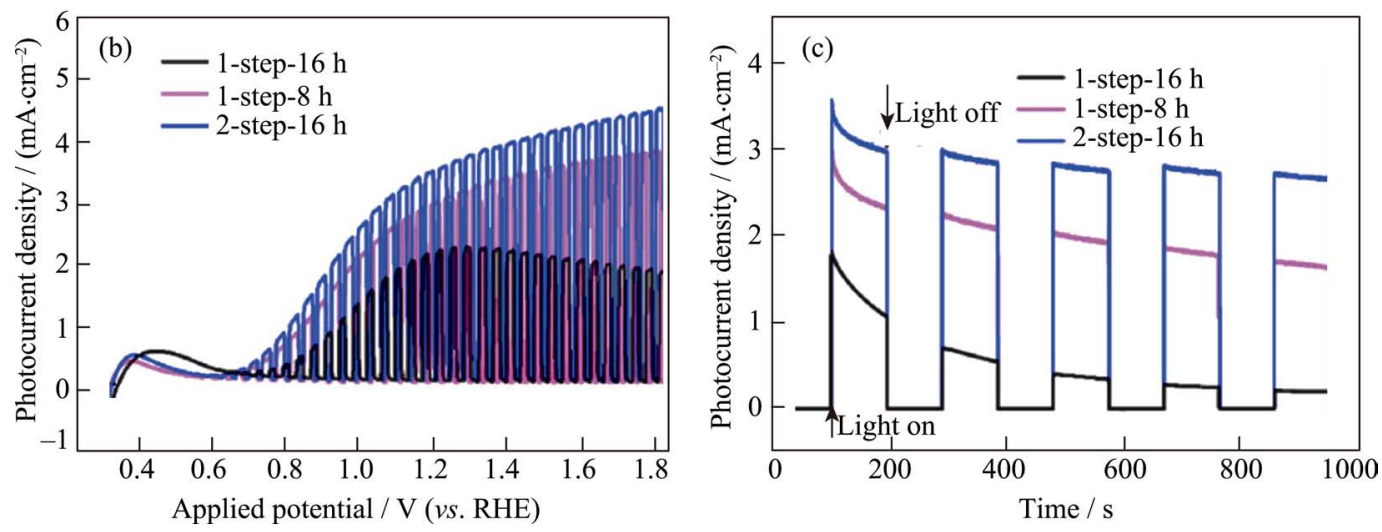

Fig. 5 (a) Schematic illustration of crystal facet orientation of the 1-step-16 h, 1-step-8 h and 2-step-16 h $\mathrm{WO}_{3}$ photoanodes; (b) Photocurrent density vs applied potential curves; (c) I- $t$ curves of the 1-step-16 h, 1-step-8 h and 2-step-16 h WO $\mathrm{W}_{3}$ photoanodes Reproduced with permission from Ref. [73]. Copyright 2016 Elsevier

(Fig. 6(a) $)^{[76]}$. A weak electronic interaction between the trapped $\mathrm{N}_{2}$ molecules and the $\mathrm{WO}_{3}$ matrix brings the $\mathrm{CB}$ and $\mathrm{VB}$ closer in energy, resulting in significant decrease of bandgap (Fig. 6(b)). In particular, the $0.039 \mathrm{~N}_{2} \cdot \mathrm{WO}_{3}$ photoanode can generate photocurrents under light illumination with a wavelength up to $640 \mathrm{~nm}$. Unfortunately, nitrogen doped $\mathrm{WO}_{3}$ photoanodes exhibited lower photocurrent densities than the undoped samples even though the bandgap could be drastically reduced ${ }^{[77]}$. The highly defective lattices of nitrogen doped $\mathrm{WO}_{3}$ photoanodes worsen the electron transport properties, resulting in poor PEC performance. On the other hand, cation doping can replace $\mathrm{W}^{6+}$ ions in the crystal lattice of $\mathrm{WO}_{3}$ and generate impurity energy levels within the visible range $^{[74]}$. For example, gadolinium (Gd) doping not only reduced the bandgap, but also lifted the VB and CB positions of $\mathrm{WO}_{3}$, resulting in the extension of light absorption edge and the increase of reduction ability ${ }^{[78]}$. Moreover, the formation of gadolinium oxide on the surface of the $\mathrm{WO}_{3}$ film can function as a passivation layer, reducing surface charge recombination. As a result, 153\% enhancement of the photocurrent density is observed. Similarly, Sm doping is also efficient to enhance the PEC performance of $\mathrm{WO}_{3}$ photoanodes ${ }^{[79]}$. Recently, $\mathrm{Na}$ doped $\mathrm{WO}_{3}$ photoanodes were found to extend the light absorption edge ${ }^{[80]}$. In the presence of $\left[\mathrm{PMo}_{12} \mathrm{O}_{40}\right]^{3-}$ or $\left[\mathrm{PW}_{12} \mathrm{O}_{40}\right]^{3-}$ as molecular OECs, the 0.4 at\% Na-doped $\mathrm{WO}_{3}$ photoanode exhibits an impressive photocurrent density of $4.5 \mathrm{~mA} / \mathrm{cm}^{2}$ at 1-1.1 V vs RHE under AM $1.5 \mathrm{G}$ illumination. Creating oxygen vacancies and low oxidation state of tungsten ions (e.g. $\mathrm{W}^{5+}$ ) through hydrogen treatment or electrochemical treatment can also enhance the PEC performance of $\mathrm{WO}_{3}$ photoanodes ${ }^{[81-82]}$. Recently, a mesoporous $\mathrm{WO}_{3}$ photoanode with dual oxygen and tungsten vacancies on the surface was prepared by a facile solution-based process ${ }^{[83]}$. The surface amorphous $\mathrm{WO}_{3}$ layer with dual oxygen and tungsten vacancies can improve the charge transfer efficiency and increase the charge carrier density of the $\mathrm{WO}_{3}$ photoanode, resulting in a photocurrent density 2.4 times higher than the untreated sample. Interestingly, DFT calculations predicted that Hf dopants and the simultaneous generation of oxygen vacancies $\left(\mathrm{V}_{\mathrm{O}}\right)$ not only reduce the bandgap but also shift both VB and CB to higher energies, which is beneficial for photocatalytic hydrogen production ${ }^{[84]}$. In addition, co-doping $\mathrm{WO}_{3}$ with $\mathrm{Hf}+2 \mathrm{~F}$ or $\mathrm{Hf}+\mathrm{S}$ is also efficient to reduce the bandgap while lifting the CB. This work provides a potential strategy for tailoring the electronic structure of $\mathrm{WO}_{3}$ toward enhanced light harvesting and increased reduction capability. However, experimental works of $\mathrm{Hf}$ doped $\mathrm{WO}_{3}$ photoanodes are still lacking.

Combining $\mathrm{WO}_{3}$ with other materials to form heterojunctions is also effective to improve the PEC performance $^{[85]}$. Due to the built-in electrical potential in the interfaces, photogenerated electrons and holes can be separated in the two constructed materials, which effectively suppress charge recombination. Moreover, the introduction of smaller bandgap semiconductors, plasmonic metals, or carbon quantum dots (CQDs) can effectively enhance the light harvesting. For example, branched $\mathrm{WO}_{3}$ nanosheet array coupled with layered $\mathrm{C}_{3} \mathrm{~N}_{4}$ 

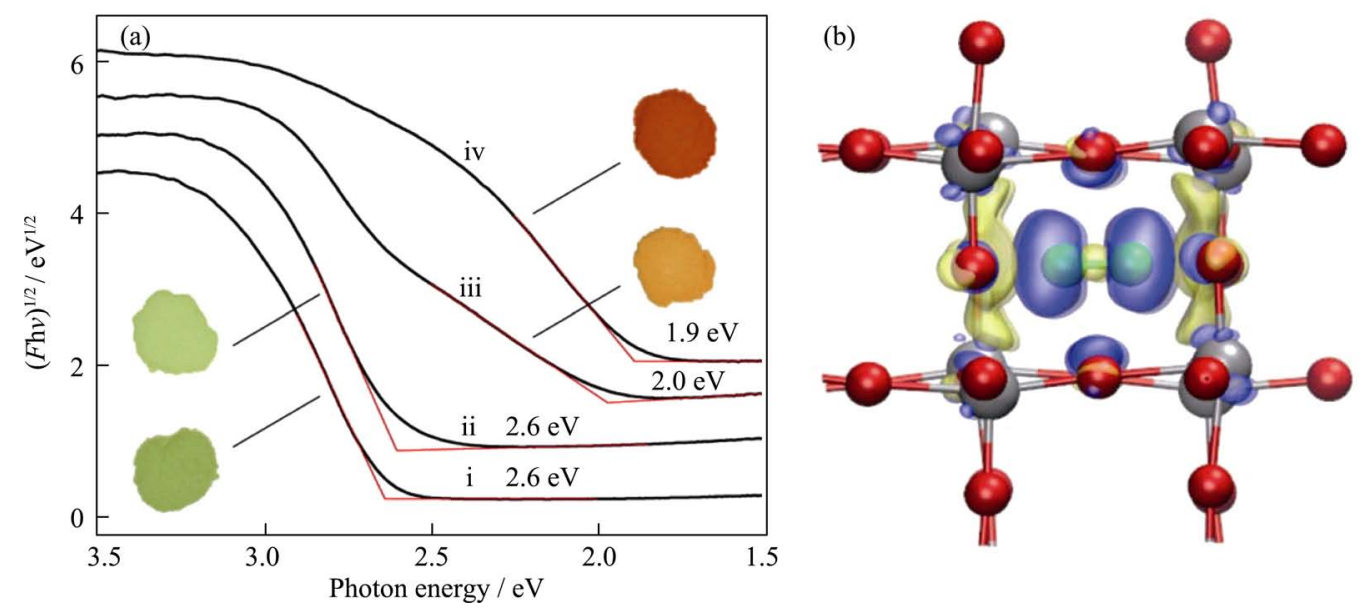

Fig. 6 (a) Diffuse reflectance spectra and digital images of (i) pure monoclinic $\mathrm{WO}_{3}$, (ii) $0.034 \mathrm{~N}_{2} \cdot \mathrm{WO}_{3}$, (iii) $0.039 \mathrm{~N}_{2} \cdot \mathrm{WO}_{3}$, and (iv) $0.039 \mathrm{~N}_{2} \cdot \mathrm{WO}_{3}$; (b) A model of electron density difference for monoclinic $\mathrm{WO}_{3}$ with incorporating $\mathrm{N}_{2}$. Yellow: electron loss; blue: electron gain; silver sphere: $\mathrm{W}$; red sphere: $\mathrm{O}$; green sphere: $\mathrm{N}$

Reproduced with permission from Ref. [76]. Copyright 2012 American Chemical Society

heterojunctions ( $\left.\mathrm{WO}_{3}-\mathrm{NA} / \mathrm{C}_{3} \mathrm{~N}_{4}-\mathrm{NS}\right)$ exhibited much higher photocurrent densities than the $\mathrm{WO}_{3}$-NA photoanode ${ }^{[86]}$. A remarkable photocurrent density of $5.76 \mathrm{~mA} / \mathrm{cm}^{2}$ is achieved at $2.1 \mathrm{~V}$ (vs RHE) under AM $1.5 \mathrm{G}$ illumination when loading $\mathrm{CoO}_{x}$ as OECs. The excellent PEC performance is attributed to the enhanced light harvesting, efficient charge separation, fast charge transfer at the interfaces, and the unique 3D layered nanostructure. In recent years, other $\mathrm{WO}_{3}$ based heterojunctions for PEC water splitting including $\mathrm{WO}_{3} / \mathrm{Bi}_{2} \mathrm{~S}_{3}{ }^{[87]}, \mathrm{WO}_{3} / \mathrm{Cu}_{2} \mathrm{O}^{[88]}$,

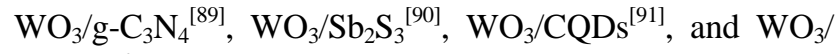
$\mathrm{AgNP}^{[92]}$ have been developed.

\section{$1.2 \alpha-\mathrm{Fe}_{2} \mathrm{O}_{3}$ photoanodes}

Hematite $\left(\alpha-\mathrm{Fe}_{2} \mathrm{O}_{3}\right)$ is earth abundant, non-toxic and stable in aqueous solutions under light illumination. With a bandgap of 1.9-2.2 eV, $\alpha-\mathrm{Fe}_{2} \mathrm{O}_{3}$ can obtain a maximum STH efficiency of $\sim 16.0 \%$ under AM 1.5 G illumination $^{[93]}$. Thus, $\alpha-\mathrm{Fe}_{2} \mathrm{O}_{3}$ is a potentially excellent photoanode material for PEC water splitting, which has attracted great attention. However, the intrinsic drawbacks such as extremely short hole diffusion length (2$4 \mathrm{~nm}$ ), very short excited state lifetime ( $\sim \mathrm{ps})$, and low conductivity, cause severe charge recombination in pure $\alpha-\mathrm{Fe}_{2} \mathrm{O}_{3}$ photoanodes, resulting in very low photocurrent densities ${ }^{[94-95]}$. In addition, the CB position of $\alpha-\mathrm{Fe}_{2} \mathrm{O}_{3}$ photoanodes is thermodynamically unfavourable for HER and the surface kinetics for OER is very poor ${ }^{[96]}$, and therefore a high external bias is required for PEC water splitting. Over the past decades, even though numerous achievements have been made, it is still very challenging to overcome the intrinsic drawbacks of $\alpha-\mathrm{Fe}_{2} \mathrm{O}_{3}$ photoanodes toward efficient, cost-effective and sustainable PEC water splitting.

Due to the extremely short hole-diffusion length, it is important to control the nanostructures of $\alpha-\mathrm{Fe}_{2} \mathrm{O}_{3}$ photoanodes to reduce the migration distance of holes to the surface for $\mathrm{OER}^{[97]}$. Moreover, doping can improve the conductivity and tune the electronic structures, whereas OECs are efficient to accelerate the surface kinetics. Therefore, the combination of nanostructural control, doping, and surface modification with OECs such as Co-Pi ${ }^{[97-99]}, \mathrm{Co}_{3} \mathrm{O}_{4}{ }^{[100-101]}, \mathrm{FeOOH}^{[102-103]}, \mathrm{NiOOH}^{[104]}, \mathrm{Ni}$ : $\mathrm{FeOOH}^{[105]}, \mathrm{NiFeO}_{x}^{[106]}$, and cobalt iron oxide (CIO) ${ }^{[107]}$ are necessary to improve the photocurrent density and lower the onset potentials for $\alpha-\mathrm{Fe}_{2} \mathrm{O}_{3}$ photoanodes. An early work reported that silicon doped nanocrystalline $\alpha-\mathrm{Fe}_{2} \mathrm{O}_{3}$ photoanodes fabricated by atmospheric pressure chemical vapor deposition (APCVD) exhibit a 90\% enhanced photocurrent density at $1.23 \mathrm{~V}$ (vs RHE) under AM $1.5 \mathrm{G}$ illumination ${ }^{[108]}$. In addition, silicon doping decreases the size of the $\alpha-\mathrm{Fe}_{2} \mathrm{O}_{3}$ nanocrystallites, which is also beneficial for charge separation. The optimized conditions of APCVD in terms of controlling the feature size, film thickness, and silicon doping of $\alpha-\mathrm{Fe}_{2} \mathrm{O}_{3}$ photoanodes with enhanced PEC performance were further studied $^{[109]}$. Depositing Co-Pi as OECs on the mesostructured Si-doped $\alpha-\mathrm{Fe}_{2} \mathrm{O}_{3}$ photoanodes reduced the external potential required for PEC water splitting by $>350 \mathrm{mV}^{[110]}$. Further studies found that a Si-doped $\alpha-\mathrm{Fe}_{2} \mathrm{O}_{3}$ photoanode deposited with a thick layer of CoPi suffers a kinetic bottleneck, limiting the PEC performance ${ }^{[111]}$. Such limitation can be greatly overcome by more sparse deposition of $\mathrm{Co}-\mathrm{Pi}$ on the Si-doped $\alpha-\mathrm{Fe}_{2} \mathrm{O}_{3}$ photoanode. The methods for depositing Co-Pi on Si-doped $\alpha-\mathrm{Fe}_{2} \mathrm{O}_{3}$ photoanodes also affect the PEC performance. By comparing with electrodeposition of $\mathrm{Co}-\mathrm{Pi}$ and $\mathrm{Co}^{2+}$ wet impregnation, the Si doped $\alpha-\mathrm{Fe}_{2} \mathrm{O}_{3}$ photoanode with Co-Pi OECs grown via photo-assisted 
electrodeposition showed superior PEC performance ${ }^{[112]}$. More uniform Co-Pi can be grown onto $\mathrm{Si}$ doped $\alpha-\mathrm{Fe}_{2} \mathrm{O}_{3}$ photoanodes by photo-assisted electrodeposition when compared to electrodeposition, resulting in a $\sim 170 \mathrm{mV}$ cathodic shift of onset potential and a stable photocurrent density of $2.8 \mathrm{~mA} / \mathrm{cm}^{2}$ at $1.23 \mathrm{~V}$ ( $v s \mathrm{RHE}$ ) under AM $1.5 \mathrm{G}$ illumination (Fig. 7). Moreover, $\mathrm{IrO}_{2}$ is also efficient OECs to further enhance the PEC performance of $\mathrm{Si}$ doped $\alpha-\mathrm{Fe}_{2} \mathrm{O}_{3}$ photoanodes ${ }^{[113]}$. However, the utilization of expensive $\mathrm{IrO}_{2}$ for modifying the low-cost $\mathrm{Fe}_{2} \mathrm{O}_{3}$ photoanodes is not favourable for cost-effective PEC water splitting. In addition, the high cost of APCVD for preparing $\mathrm{Si}$ doped $\alpha-\mathrm{Fe}_{2} \mathrm{O}_{3}$ photoanodes is also not feasible for scale-up applications. It may be challenging to achieve Si doping by other low-cost wet chemical processes. Therefore, it is more desirable to develop other low-cost wet chemical methods with proper doping to enhance the PEC performance of $\alpha-\mathrm{Fe}_{2} \mathrm{O}_{3}$ photoanodes.

In addition to $\mathrm{Si}$, other earth-abundant metal elements such as $\mathrm{Sn}, \mathrm{Ti}, \mathrm{Mo}, \mathrm{Cr}, \mathrm{Al}, \mathrm{Zr}$, and $\mathrm{Nb}$ are also efficient to improve the PEC performance of $\mathrm{Fe}_{2} \mathrm{O}_{3}$ photoanodes $^{[104,114-119]}$. Encouragingly, such dopants can be achieved in wet-chemical available $\mathrm{Fe}_{2} \mathrm{O}_{3}$ photoanodes, which can greatly reduce the fabrication cost. Grätzel's group first reported that relatively high photocurrent densities for PEC water splitting can be achieved with mesoporous $\alpha-\mathrm{Fe}_{2} \mathrm{O}_{3}$ photoanodes prepared by a solution-based colloidal method followed by annealing at $800^{\circ} \mathrm{C}$ (Fig. 8(a) $)^{[120]}$. The diffusion of Sn atoms from the FTO substrates to $\alpha-\mathrm{Fe}_{2} \mathrm{O}_{3}$ takes place at $800^{\circ} \mathrm{C}$, functioning as electron donating substitutional impurities $\left(\mathrm{Sn}^{4+}\right)$. While the signal of $\mathrm{Sn}^{4+}$ cannot be detected when the calcination temperatures are 400 or $700^{\circ} \mathrm{C}$ (Fig. 8(b)).

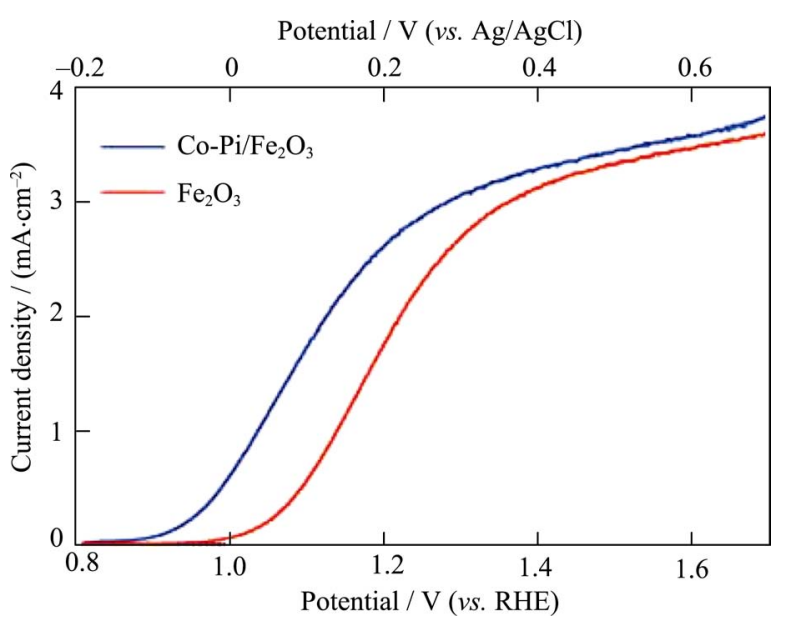

Fig. 7 Dark-current (dotted) and photocurrent (solid) densities of bare $\alpha-\mathrm{Fe}_{2} \mathrm{O}_{3}$ and $\mathrm{Co}-\mathrm{Pi} / \alpha-\mathrm{Fe}_{2} \mathrm{O}_{3}$ photoanodes modified by photo-assisted electrodeposition

Reproduced with permission from Ref. [112]. Copyright 2011 Royal Society of Chemistry
Moreover, the calcination temperature of $800^{\circ} \mathrm{C}$ is essential to increase the absorption coefficient by up to a factor of 2 due to the structural distortion effect (Fig. 8(c)). However, the increased particle size after high temperature calcination may have detrimental effects on charge separation. Encapsulating the $\mathrm{Ti}$ doped $\alpha-\mathrm{Fe}_{2} \mathrm{O}_{3}$ structures with a conformal silica layer is efficient to prevent the further growth of the particles during high temperature $\left(800^{\circ} \mathrm{C}\right)$ calcination $^{[121]}$. The final porous $\mathrm{Ti}$ doped $\alpha-\mathrm{Fe}_{2} \mathrm{O}_{3}$ photoanode can be achieved by removing the conformal silica layer, which exhibits enhanced photocurrent densities compared to its counterpart without the silica layer. Very recently, a similar strategy was applied to protect the $\alpha-\mathrm{Fe}_{2} \mathrm{O}_{3}$ nanorod arrays after calcination at $800^{\circ} \mathrm{C}$, which effectively keeps the nanorod structures with uniform distribution of Sn doping ${ }^{[122]}$. Interestingly, depositing a $\mathrm{ZrO}_{2}$ thin layer on the $\mathrm{FeOOH}$ nanorods not only can keep the $1 \mathrm{D}$ structures after high temperature $\left(800^{\circ} \mathrm{C}\right)$ calcination, but also can convert the $\mathrm{FeOOH}$ nanorods to $\mathrm{Zr}$ doped $\alpha-\mathrm{Fe}_{2} \mathrm{O}_{3}$ nanotubes ${ }^{[123]}$. Although activating $\alpha-\mathrm{Fe}_{2} \mathrm{O}_{3}$ photoanodes by a high-temperature $\left(800^{\circ} \mathrm{C}\right)$ annealing treatment is efficient to improve the PEC performance, the fragile FTO substrates would be destroyed if the annealing time were too long (>10 min $)^{[124]}$. In this regard, a post growth doping technique was proposed, in which $\mathrm{Ti}$ or $\mathrm{Zr}$ precursor solution was deposited on $\alpha-\mathrm{Fe}_{2} \mathrm{O}_{3}$ nanostructures followed by subsequent calcination in air at a lower temperature of $650-700^{\circ} \mathrm{C}^{[125]}$. By depositing a thin $\mathrm{TiO}_{2}$ layer on the FTO substrates for the subsequent growth of $\alpha-\mathrm{Fe}_{2} \mathrm{O}_{3}$ nanostructures, the activation temperature was reduced to $600^{\circ} \mathrm{C}^{[126]}$. Interestingly, Ge-doped $\alpha-\mathrm{Fe}_{2} \mathrm{O}_{3}$ photoanodes could achieve optimized PEC performance at a calcination temperature of only $550^{\circ} \mathrm{C}^{[127]}$.

The photocurrent densities of most modified $\alpha-\mathrm{Fe}_{2} \mathrm{O}_{3}$ photoanodes are less than $3.5 \mathrm{~mA} / \mathrm{cm}^{2}$ even at high applied potentials. Surprisingly, Co-Pi modified Pt doped $\alpha-\mathrm{Fe}_{2} \mathrm{O}_{3}$ photoanodes led to a record-breaking photocurrent density of $4.32 \mathrm{~mA} / \mathrm{cm}^{2}$ at $1.23 \mathrm{~V}$ (vs RHE) under AM $1.5 \mathrm{G}$ illumination ${ }^{[128]}$. Furthermore, the co-doping of $\mathrm{Ru}$ cations with different valence states were efficient to boost the PEC performance of $\alpha-\mathrm{Fe}_{2} \mathrm{O}_{3}$ photoanodes ${ }^{[129]}$. Even without OECs, the optimized Ru-doped $\alpha-\mathrm{Fe}_{2} \mathrm{O}_{3}$ photoanode with a $\mathrm{Fe} / \mathrm{Ru}$ molar ratio of 100/5 exhibits an onset potential of approximately $0.7 \mathrm{~V}$ ( vs RHE) and an impressive photocurrent density of $5.7 \mathrm{~mA} / \mathrm{cm}^{2}$ at $1.23 \mathrm{~V}$ (vs RHE) under AM 1.5 G illumination. The excellent PEC performance is attributed to the increase of charge carrier concentration and mobility, and the significant decrease of defects after co-doping of Ru cations with different valence states. Although noble metal dopants can 

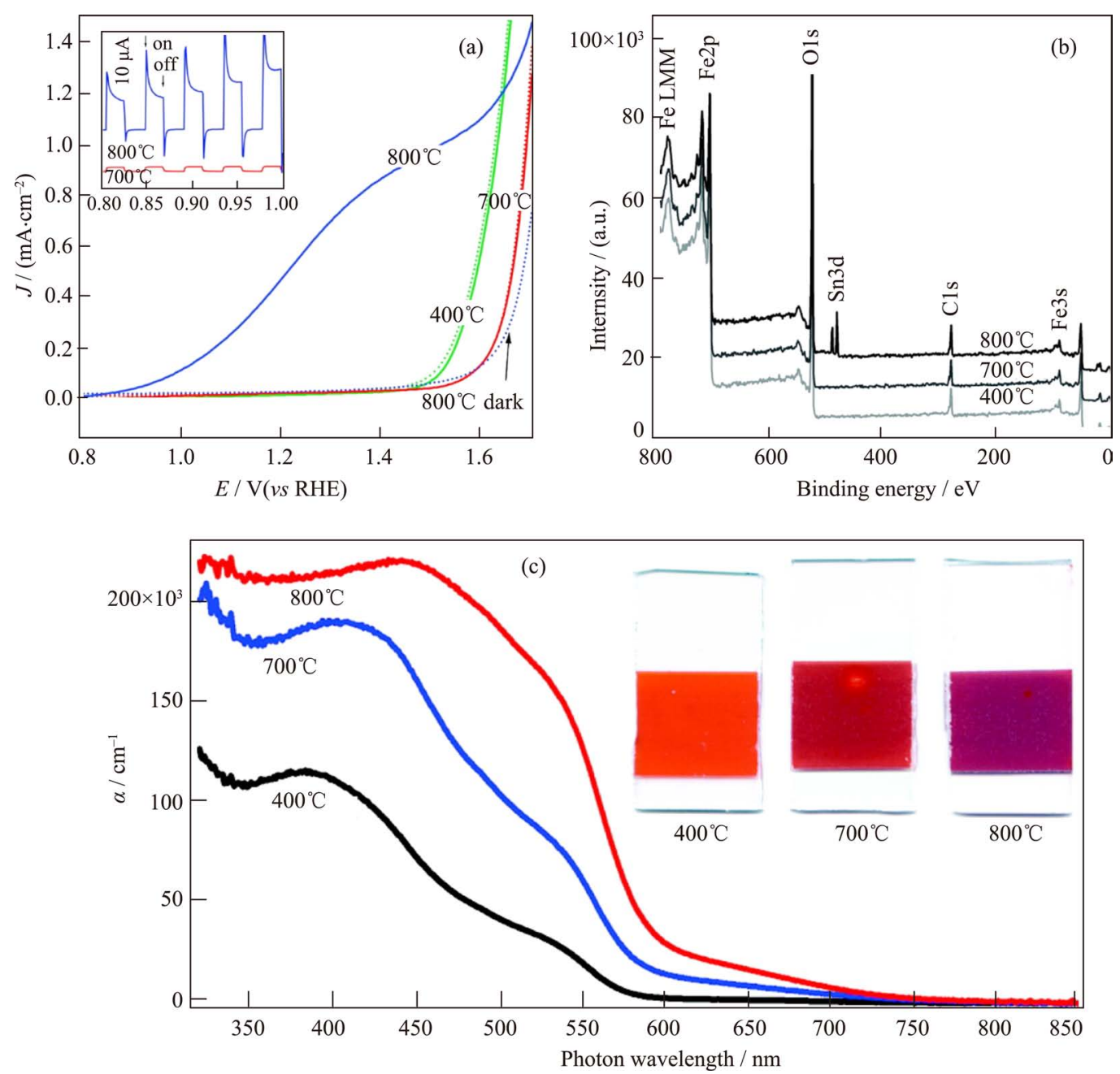

Fig. 8 (a) Photocurrent density $v$ s applied potential curves of $\alpha-\mathrm{Fe}_{2} \mathrm{O}_{3}$ photoanodes sintered at 400,700 , and $800^{\circ} \mathrm{C}$ in the dark (dotted curves) and under AM $1.5 \mathrm{G}$ illumination (solid curves) with inset showing enlarged curves photocurrent density vs applied potential curves of $\alpha-\mathrm{Fe}_{2} \mathrm{O}_{3}$ photoanodes sintered at 700 and $800^{\circ} \mathrm{C}$; (b) XPS survey data for the $\alpha$ - $\mathrm{Fe}_{2} \mathrm{O}_{3}$ photoanodes

sintered at 400, 700, and $800^{\circ} \mathrm{C}$; (c) Absorption coefficient as a function of wavelength and the digital images of the $\alpha-\mathrm{Fe}_{2} \mathrm{O}_{3}$ photoanodes sintered at 400,700 , and $800^{\circ} \mathrm{C}$

Reproduced with permission from Ref. [120]. Copyright 2010 American Chemical Society

greatly enhance the PEC performance of $\alpha-\mathrm{Fe}_{2} \mathrm{O}_{3}$ photoanodes, the scale-up application may be an issue. Further studies to understand the fundamental mechanisms of noble metal dopants for improving the PEC performance of $\alpha-\mathrm{Fe}_{2} \mathrm{O}_{3}$ photoanodes are required, which may provide useful information for seeking alternative strategies.

To explore low-cost $\alpha-\mathrm{Fe}_{2} \mathrm{O}_{3}$ photoanodes for efficient PEC water splitting, our group innovatively developed $\mathrm{Co}-\mathrm{Pi} / \mathrm{Ag} / \alpha-\mathrm{Fe}_{2} \mathrm{O}_{3}$ photoanodes by modifying the $\alpha-\mathrm{Fe}_{2} \mathrm{O}_{3}$ nanosheet arrays with low-cost $\mathrm{Ag}$ and $\mathrm{Co}-\mathrm{Pi}$ nanoparticles (NPs) ${ }^{[130]}$. Pure $\alpha-\mathrm{Fe}_{2} \mathrm{O}_{3}$ nanosheet arrays with enrich $\{110\}$ facets were prepared by anodizing the Fe foils in an ethylene glycol electrolyte containing fluorine ions, which exhibits a high photocurrent density of $1.5 \mathrm{~mA} / \mathrm{cm}^{2}$ at $1.23 \mathrm{~V}$ (vs RHE) under AM $1.5 \mathrm{G}$ illumination. By modifying the surfaces with plasmonic Ag NPs and $\mathrm{Co}-\mathrm{Pi}$, the light harvesting, charge transfer, and sur- face charge separation can be effectively improved, resulting in an impressive photocurrent density of $4.68 \mathrm{~mA} / \mathrm{cm}^{2}$ at $1.23 \mathrm{~V}$ (vs RHE) under AM $1.5 \mathrm{G}$ illumination. The obtained $\mathrm{Co}-\mathrm{Pi} / \mathrm{Ag} / \alpha-\mathrm{Fe}_{2} \mathrm{O}_{3}$ photoanode is very stable and no photocurrent decay can be observed in the $5 \mathrm{~h}$ consecutive light illumination measurement (Fig. 9(a)). The electrochemical anodization method to grow $\alpha-\mathrm{Fe}_{2} \mathrm{O}_{3}$ nanostructures directly on $\mathrm{Fe}$ foils can achieve excellent interfacial contact, which may be another key factor to achieve high PEC performance. Very recently, a highly efficient $\alpha-\mathrm{Fe}_{2} \mathrm{O}_{3}$ photoanode with multidimensional nano/micro-architectures was prepared by anodizing Fe foams (AFFs), as shown in Fig. 9(b) ${ }^{[131]}$. Under AM $1.5 \mathrm{G}$ illumination, the pure $\alpha-\mathrm{Fe}_{2} \mathrm{O}_{3}$ photoanode exhibits a photocurrent density of $2.29 \mathrm{~mA} / \mathrm{cm}^{2}$ at $1.23 \mathrm{~V}$ (vs RHE). By decorating the surfaces with OECs, an impressive photocurrent density of $6.8 \mathrm{~mA} / \mathrm{cm}^{2}$ can be 

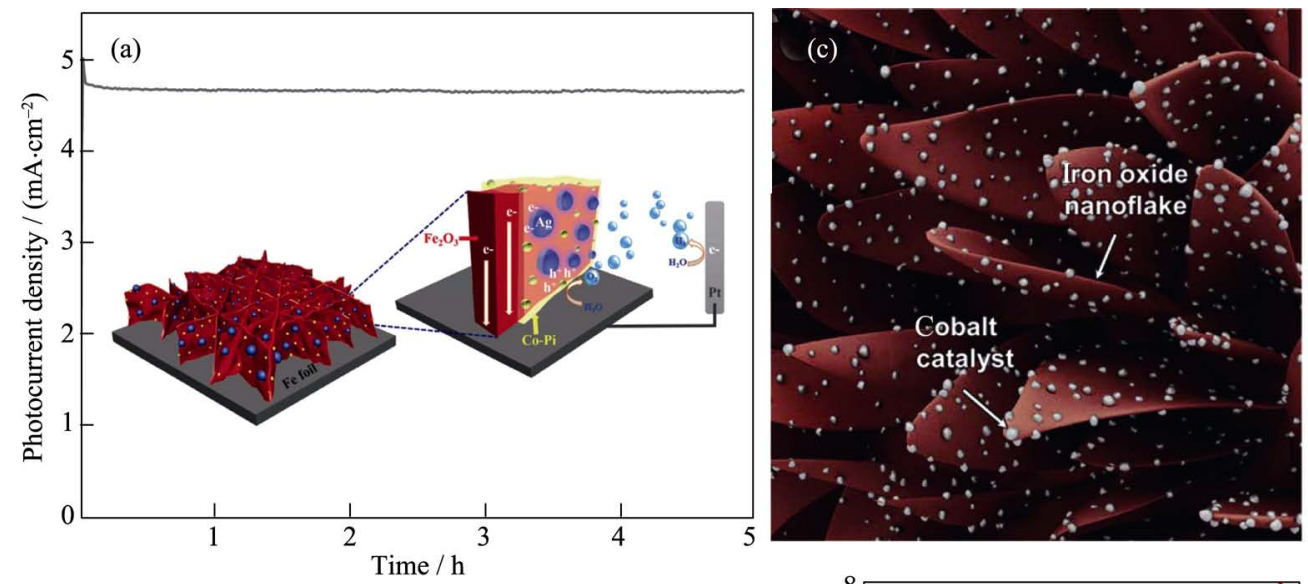

(b)
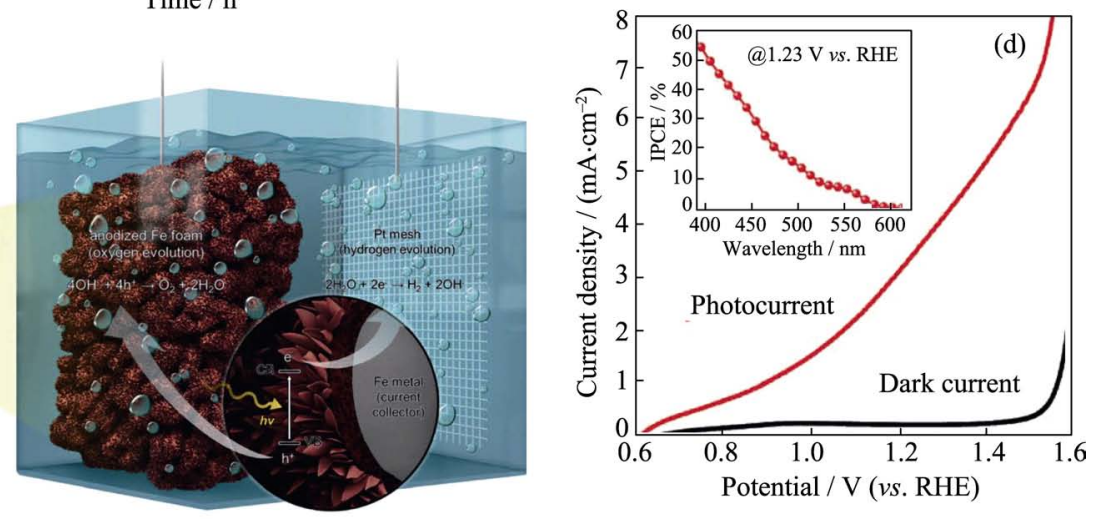

Fig. 9 (a) I-t curve of a Co-Pi/Ag/ $\alpha-\mathrm{Fe}_{2} \mathrm{O}_{3}$ photoanode with inset showing schematic of a Co-Pi/Ag/ $\alpha-\mathrm{Fe}{ }_{2} \mathrm{O}_{3}$ photoanode for efficient PEC water splitting; (b) Schematic of an AFF photoanode for PEC water splitting; (c) Schematic of Co based OECs decorated on the surfaces of an AFF photoanode; (d) Photocurrent density vs applied potential curves of a Co based OECs modified AFF photoanode with inset showing IPCE curve measured at $1.23 \mathrm{~V}$ (vs RHE)

Reproduced with permission from Ref. [130-131]. Copyright 2016 and 2017 Wiley-VCH Verlag GmbH \& Co. KGaA, Weinheim

achieved before the dark current onset (at $1.55 \mathrm{~V}$ (vs RHE), Fig. 9(c) and 9(d)). The excellent PEC performance obtained by the anodized Fe foam is attributed to the promising characteristics such as large surface area, low-dimensional confined nanostructures, and very low electrical resistance.

The construction of heterojunction can also improve the PEC performance of $\alpha-\mathrm{Fe}_{2} \mathrm{O}_{3}$ photoanodes. A threedimensional branched cobalt-doped $\alpha-\mathrm{Fe}_{2} \mathrm{O}_{3}$ nano$\mathrm{rod} / \mathrm{MgFe}_{2} \mathrm{O}_{4}$ heterojunction was grown on a $\mathrm{Ti}$ mesh, exhibiting a photocurrent density of $3.34 \mathrm{~mA} / \mathrm{cm}^{2}$ at 1.4 V (vs RHE) under AM $1.5 \mathrm{G}$ illumination ${ }^{[132]}$. The enhanced PEC performance is attributed to the excellent charge transfer, enhanced light-harvesting ability, and large contact area in the novel 3D branched structure. By decorating undoped $\alpha-\mathrm{Fe}_{2} \mathrm{O}_{3}$ NPs on $\mathrm{TiSi}_{2}$ nanonets to form heterojunctions, a high incident photon to current efficiency (IPCE) of $46 \%$ was observed at a wavelength of $400 \mathrm{~nm}$ with an applied potential of $1.53 \mathrm{~V}$ (vs RHE) ${ }^{[133]}$. Without the loading of any OECs, a photocurrent density of $2.7 \mathrm{~mA} / \mathrm{cm}^{2}$ can be achieved at $1.53 \mathrm{~V}$ (vs RHE) under AM $1.5 \mathrm{G}$ illumination. Other $\alpha-\mathrm{Fe}_{2} \mathrm{O}_{3}$ based heterojunctions such as $\mathrm{WO}_{3} / \alpha-\mathrm{Fe}_{2} \mathrm{O}_{3}$ junctions ${ }^{[134]}, \alpha-\mathrm{Fe}_{2} \mathrm{O}_{3} /$ grap- hene/ $\mathrm{BiV}_{1-x} \mathrm{Mo}_{x} \mathrm{O}_{4}$ junctions ${ }^{[135]}$, Sb-doped $\mathrm{SnO}_{2} / \alpha-\mathrm{Fe}_{2} \mathrm{O}_{3}$ junctions ${ }^{[136]}$, Ti doped $\alpha-\mathrm{Fe}_{2} \mathrm{O}_{3} / \mathrm{ZnFe}_{2} \mathrm{O}_{4}$ junctions ${ }^{[137]}$, $\mathrm{CaFe}_{2} \mathrm{O}_{4} / \alpha-\mathrm{Fe}_{2} \mathrm{O}_{3}$ junctions ${ }^{[138]}$, and $\alpha-\mathrm{Fe}_{2} \mathrm{O}_{3} / \mathrm{FeTiO}_{2}$ junctions $^{[139-141]}$ have been developed.

\section{3 $\mathrm{BiVO}_{4}$ photoanodes}

As an earth abundant, low cost, stable, and narrow bandgap semiconductor, bismuth vanadate $\left(\mathrm{BiVO}_{4}\right)$ has attracted intensive studies as promising photoanodes for PEC water splitting ${ }^{[142]}$. The bandgap of $\mathrm{BiVO}_{4}$ is $2.4 \mathrm{eV}$, corresponding to a theoretical photocurrent density of $7.5 \mathrm{~mA} / \mathrm{cm}^{2}$ under standard AM $1.5 \mathrm{G}$ solar light irradiation ${ }^{[45]}$. Thermodynamically, the $\mathrm{CB}$ of $\mathrm{BiVO}_{4}$ is located just short of the proton reduction potential ${ }^{[143]}$. Consequently, only a small external bias is required to achieve PEC water splitting. Moreover, the charge carrier lifetime ( 40 ns) and hole diffusion length ( 70 nm) of $\mathrm{BiVO}_{4}$ are much longer than $\alpha-\mathrm{Fe}_{2} \mathrm{O}_{3}{ }^{[144]}$. However, $\mathrm{BiVO}_{4}$ suffers severe charge recombination due to sluggish electron transport properties and poor surface kinetics ${ }^{[145]}$. Many strategies have been explored to solve the above issues and the PEC performance of $\mathrm{BiVO}_{4}$ photoanodes has been improved significantly.

Doping is efficient to improve the electron transport 
properties of $\mathrm{BiVO}_{4}$, reducing charge recombination in the bulk. So far, only Mo, W, and P dopants can significantly enhance the PEC performance of $\mathrm{BiVO}_{4}$ photoanodes, which has been intensively investigated. For example, $2.5 \% \mathrm{~W}$ doped $\mathrm{BiVO}_{4}$ and $5 \%$ Mo doped $\mathrm{BiVO}_{4}$ could generate photocurrent densities that were 7 and 8 folds higher than the pure $\mathrm{BiVO}_{4}$ photoanode, respectively ${ }^{[146]}$. Moreover, $\mathrm{Mo} / \mathrm{W}$ codoped $\mathrm{BiVO}_{4}$ can further improve the PEC performance. With simultaneous incorporation of $6 \%$ Mo and $2 \% \mathrm{~W}$, the photocurrent densities are enhanced by 10 folds compared to the pure $\mathrm{BiVO}_{4}$ photoanode. Interestingly, a gradient doping technique was developed to prepare a distributed $n^{+}-n$ $\mathrm{BiVO}_{4}$ homojunction, which exhibits an excellent carrier-separation efficiency up to $60 \%$ at $1.23 \mathrm{~V}$ (vs RHE) under AM $1.5 \mathrm{G}$ illumination ${ }^{[147]}$. The unique property of gradient $\mathrm{W}$ doped $\mathrm{BiVO}_{4}$ is shown in Fig. 10. Compared to $\mathrm{W}$ doped $\mathrm{BiVO}_{4}$ (Fig. 10(a)), $\mathrm{W}$ doped $\mathrm{BiVO}_{4}$ homojunction (Fig. 10(b)) and $\mathrm{W}$ doped $\mathrm{BiVO}_{4}$ reverse homojunction (Fig. 10(c)) can generate band bending in the interfaces. However, gradient $\mathrm{W}$ doped $\mathrm{BiVO}_{4}$ extends the presence of band bending over the entire thickness of the photoanode (Fig. 10(d)), which is more efficient for charge separation (Fig. 10(e)). By loading Co-Pi OECs to further reduce the surface charge recombination, a photocurrent density of $3 \mathrm{~mA} / \mathrm{cm}^{2}$ can be achieved at $1.23 \mathrm{~V}$ (vs RHE) under AM 1.5 G illumination. On the other hand,
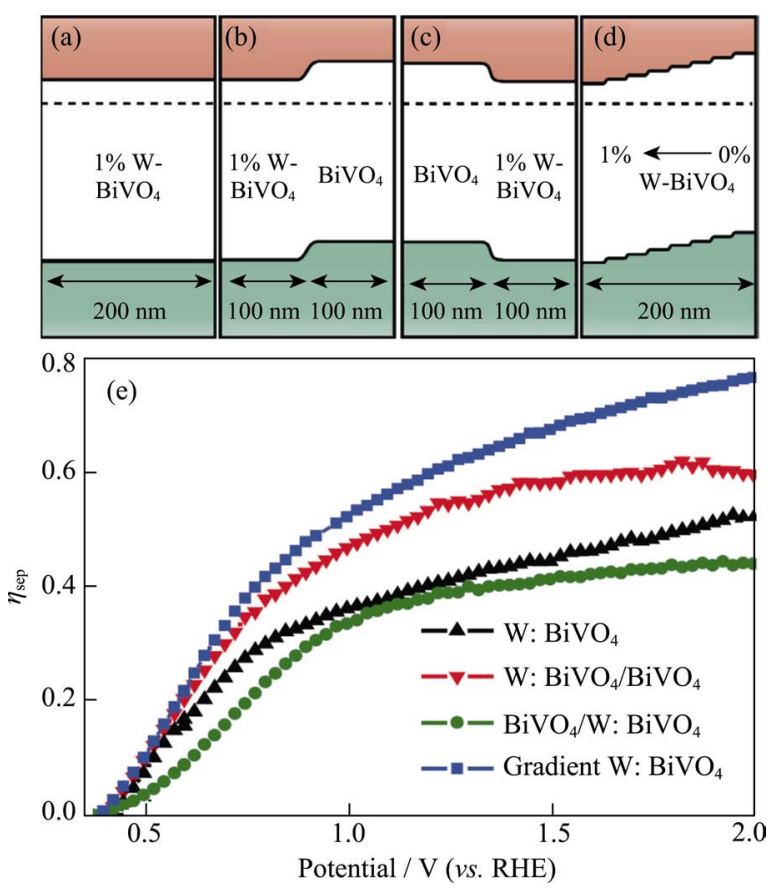

Fig. 10 Band diagram schematic of the $\mathrm{BiVO}_{4}$ samples (a) $1 \% \mathrm{~W}$-doped $\mathrm{BiVO}_{4}$; (b) $\mathrm{W}$ doped $\mathrm{BiVO}_{4}$ homojunction; (c) $\mathrm{W}$ doped $\mathrm{BiVO}_{4}$ reverse homojunction; (d) Gradient $\mathrm{W}$ doped $\mathrm{BiVO}_{4}$; (e) Carrier separation efficiency curves

Reproduced with permission from Ref. [147]. Copyright 2013 Nature Publishing Group creating defects such as oxygen vacancies in the $\mathrm{BiVO}_{4}$ crystals, namely self-doping, is also efficient to enhance the PEC performance. Oxygen vacancies and hydrogen impurities were introduced in the $\mathrm{BiVO}_{4}$ photoanodes through hydrogen treatment ${ }^{[148]}$. DFT calculations reveal that both oxygen vacancies and hydrogen impurities are shallow donors for $\mathrm{BiVO}_{4}$ with low formation energies, which effectively enhances the donor densities of $\mathrm{BiVO}_{4}$ without introducing deep trap states. As a result, a maximum photocurrent density of $3.5 \mathrm{~mA} / \mathrm{cm}^{2}$ is achieved at $1.0 \mathrm{~V}$ (vs $\mathrm{Ag} / \mathrm{AgCl}$ ), which is one order of magnitude higher than the untreated counterpart. Self-doping can also be obtained by other mild processes, such as chemical reduction ${ }^{[149]}$ and electrochemical treatment ${ }^{[150-152]}$.

Nanostructures with large surface areas and short hole migration distances can drastically enhance bulk charge separation. Modifying the surface with OECs to further reduce surface charge recombination, high PEC performance can be obtained. For example, a nanoporous $\mathrm{BiVO}_{4}$ photoanode can effectively suppress bulk carrier recombination without additional doping, exhibiting an electron-hole separation efficiency of $90 \%$ at $1.23 \mathrm{~V}$ ( vs $\mathrm{RHE}^{[153]}$. By loading $\mathrm{FeOOH} / \mathrm{NiOOH}$ as dual-layer OECs on the surface, a remarkable photocurrent density of $2.73 \mathrm{~mA} / \mathrm{cm}^{2}$ can be achieved at a potential as low as $0.6 \mathrm{~V}$ vs the counter electrode (Fig. 11(a)). The PEC performance of the nanoporous $\mathrm{BiVO}_{4}$ photoanode can be further improved by a mild nitrogen treatment process $^{[154]}$. Surprisingly, the incorporation of nitrogen dopant and oxygen vacancies not only reduces the bandgap by $\sim 0.2 \mathrm{eV}$, but also enhances charge separation. As a result, an over 2\% PEC water splitting efficiency is attained (Fig. 11(b)). Although the above nanoporous $\mathrm{BiVO}_{4}$ photoanodes can achieve high PEC performance, the electron transport property is still poorer than the hole transport property in the film. Therefore, back illumination is required to achieve the best photocurrent densities. Interestingly, the difference of photocurrent densities under front and back illumination can be greatly reduced by modifying the synthesis conditions ${ }^{[155]}$. Furthermore, decorating the surfaces of the obtained $\mathrm{BiVO}_{4}$ photoanodes with $\mathrm{NiFeO}_{x}$-Bi OECs, stable overall water splitting can be achieved for $10 \mathrm{~h}$ (Fig. 11(c)). Very recently, molecular $\mathrm{Co}_{4} \mathrm{O}_{4}$ cubane OECs were used to modify nanoporous $\mathrm{BiVO}_{4}$ photoanodes, which exhibits an excellent photocurrent density of $5 \mathrm{~mA} / \mathrm{cm}^{2}$ at $1.23 \mathrm{~V}$ under AM 1.5 G illumination (Fig. 11(d)) ${ }^{[156]}$. Even though high photocurrent densities can be achieved using molecular cobalt cubane complex, the long-term stability is not comparable to the state-of-the-art metal oxide OECs. Along with the exploration of more efficient 

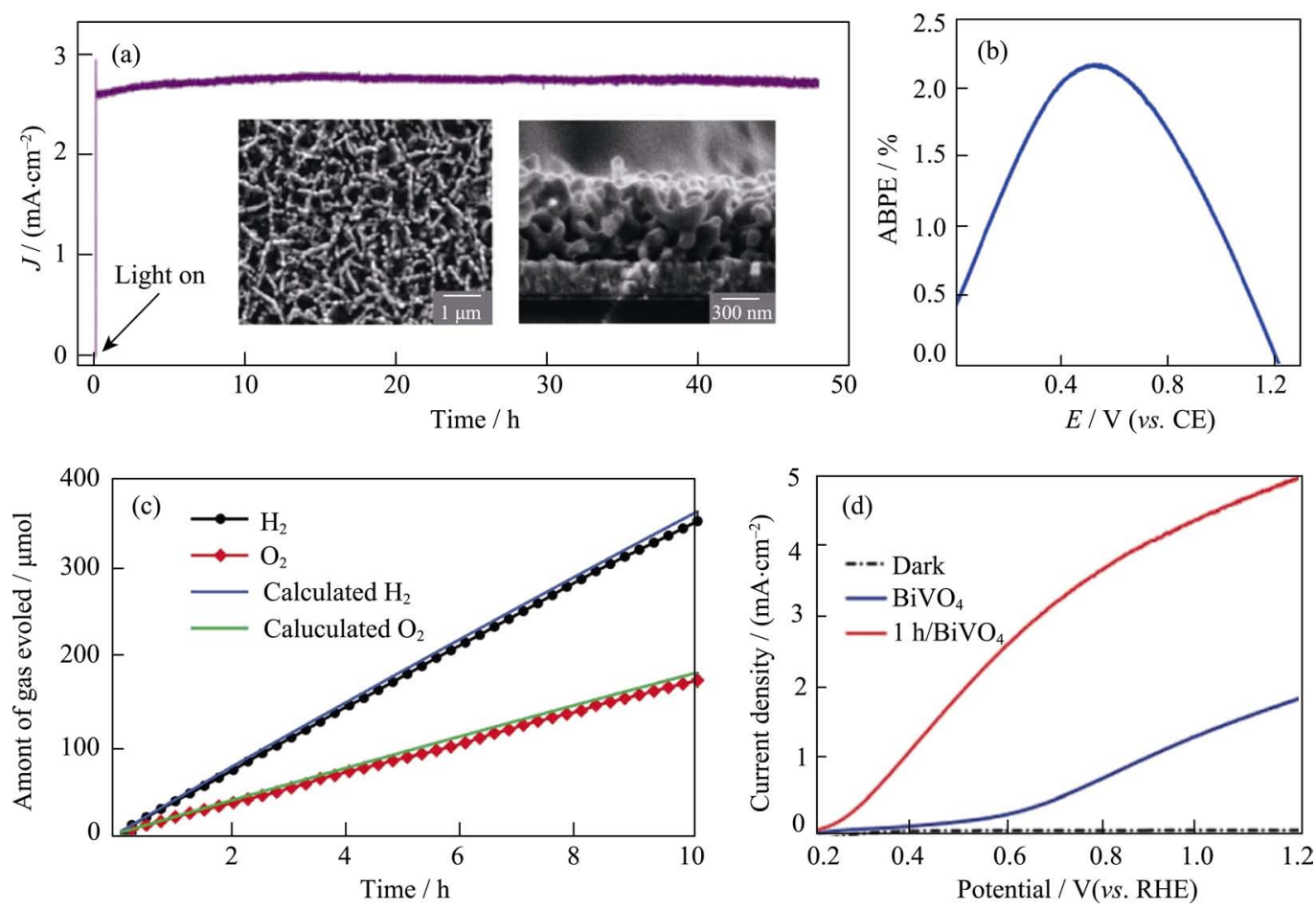

Fig. 11 (a) $I$ - $t$ curve of nanoporous $\mathrm{BiVO}_{4} / \mathrm{FeOOH} / \mathrm{NiOOH}$ photoanode measured at $0.6 \mathrm{~V}$ (vs counter electrode) with insets showing: surface and cross-sectional SEM images of nanoporous $\mathrm{BiVO}_{4}$. Reproduced with permission from Ref.[153]. Copyright 2014,

American Association for the Advancement of Science. (b) Applied bias photon-to-current efficiency (ABPE) of $\mathrm{N}_{2}$-treated $\mathrm{BiVO}_{4} / \mathrm{FeOOH} / \mathrm{NiOOH}$ photoanode obtained using a two-electrode configuration (CE: counter electrode). Reproduced with permission from Ref. [154]. Copyright 2015 Nature Publishing Group. Distributed under a CC-BY 4.0 license. (c) $\mathrm{H}_{2}$ (black circle) and $\mathrm{O}_{2}$ evolution (red square) using two $\mathrm{BiVO}_{4} / \mathrm{NiFeO}_{x}$-Bi photoanodes. Reproduced with permission from Ref. [155]. Copyright 2015 Wiley-VCH Verlag GmbH \& Co. KGaA, Weinheim. (d) Photocurrent density vs applied potential curves of $\mathrm{BiVO}_{4}$ and molecular $\mathrm{Co}_{4} \mathrm{O}_{4}$ cubane modified $\mathrm{BiVO}_{4}$ photoanodes under AM $1.5 \mathrm{G}$ illumination. Reproduced with permission from Ref. [156].

Copyright 2017 Wiley-VCH Verlag GmbH \& Co. KGaA, Weinheim

OECs, the PEC performance of nanoporous $\mathrm{BiVO}_{4}$ photoanodes can be further improved by enhancing the light harvesting through introducing CQDs as a visible light sensitizer ${ }^{[157]}$. The CQDs in the nanoporous $\mathrm{BiVO}_{4} /$ FeOOH/NiOOH photoanode not only broaden the light response range and increase charge separation, but also maintain the excellent hole transfer capacity from $\mathrm{BiVO}_{4}$ to the OEC layer. Consequently, a new record photocurrent density of $5.99 \mathrm{~mA} / \mathrm{cm}^{2}$ is attained at $1.23 \mathrm{~V}$ (vs RHE) under AM 1.5 G illumination. Moreover, stable overall water splitting can be achieved for $10 \mathrm{~h}$. Interestingly, modifying the surfaces of a bulky crystalline $\mathrm{BiVO}_{4}$ thin film with impregnated $\mathrm{CoO}_{x}$ OECs and atomiclayer deposited $\mathrm{NiO}$ can still exhibit a PEC water splitting efficiency of $1.5 \%^{[158]}$. The high activity for overall water splitting can be maintained for $12 \mathrm{~h}$, with continuous and stoichiometric $\mathrm{H}_{2}$ and $\mathrm{O}_{2}$ evolution. Compared to nanostructured $\mathrm{BiVO}_{4}$ photoanodes that require more sophisticated fabrication and modification processes, planar $\mathrm{BiVO}_{4}$ thin films may be more favourable for future industrialisation.

The formation of heterojunction is another efficient strategy to enhance the PEC performance of $\mathrm{BiVO}_{4}$ photoanodes. Owing to the matchable band edge positions, $\mathrm{WO}_{3}$ and $\mathrm{BiVO}_{4}$ can form type II heterojunctions, which is efficient for charge separation. The morphology of $\mathrm{WO}_{3}$, the size and the loading amount of $\mathrm{BiVO}_{4}$ affect the PEC performance of $\mathrm{WO}_{3} / \mathrm{BiVO}_{4}$ heterojunction photoanodes $^{[159-165]}$. Moreover, by carefully modifying the substrate, the $\mathrm{WO}_{3}$ nanorod arrays (NRs), the decorated $\mathrm{BiVO}_{4}$ particles and Co-Pi OECs, an ultimate water splitting photocurrent density of $6.72 \mathrm{~mA} / \mathrm{cm}^{2}$ is achieved at $1.23 \mathrm{~V}$ vs RHE under AM $1.5 \mathrm{G}$ illumination (Fig. 12) ${ }^{[166]}$. Due to the extremely positive $\mathrm{VB}$ and proper $\mathrm{CB}$ positions, $\mathrm{SnO}_{2}$ can serve as a hole blocking layer while allowing the transfer of electrons. Introducing a $\mathrm{SnO}_{2}$ layer between $\mathrm{WO}_{3}$ and $\mathrm{BiVO}_{4}$ to form $\mathrm{WO}_{3} / \mathrm{SnO}_{2} / \mathrm{BiVO}_{4}$ junctions can further increase charge separation ${ }^{[167]}$. In addition, using $\mathrm{SnO}_{2}$ as the bottom layer to form $\mathrm{SnO}_{2} / \mathrm{WO}_{3} / \mathrm{BiVO}_{4}$ junctions can generate higher photocurrent densities than $\mathrm{WO}_{3} / \mathrm{SnO}_{2} / \mathrm{BiVO}_{4}$ junctions, possibly due to the stepwise $\mathrm{CB}$ positions of $\mathrm{SnO}_{2}, \mathrm{WO}_{3}$, and $\mathrm{BiVO}_{4}$, enabling the formation of type II heterojunctions ${ }^{[168]}$. Interestingly, composite $\mathrm{TiO}_{2} / \mathrm{BiVO}_{4}$ photoanodes exhibit enhanced PEC performance ${ }^{[169-170]}$, which is inconsistent with the predicted Type I band 

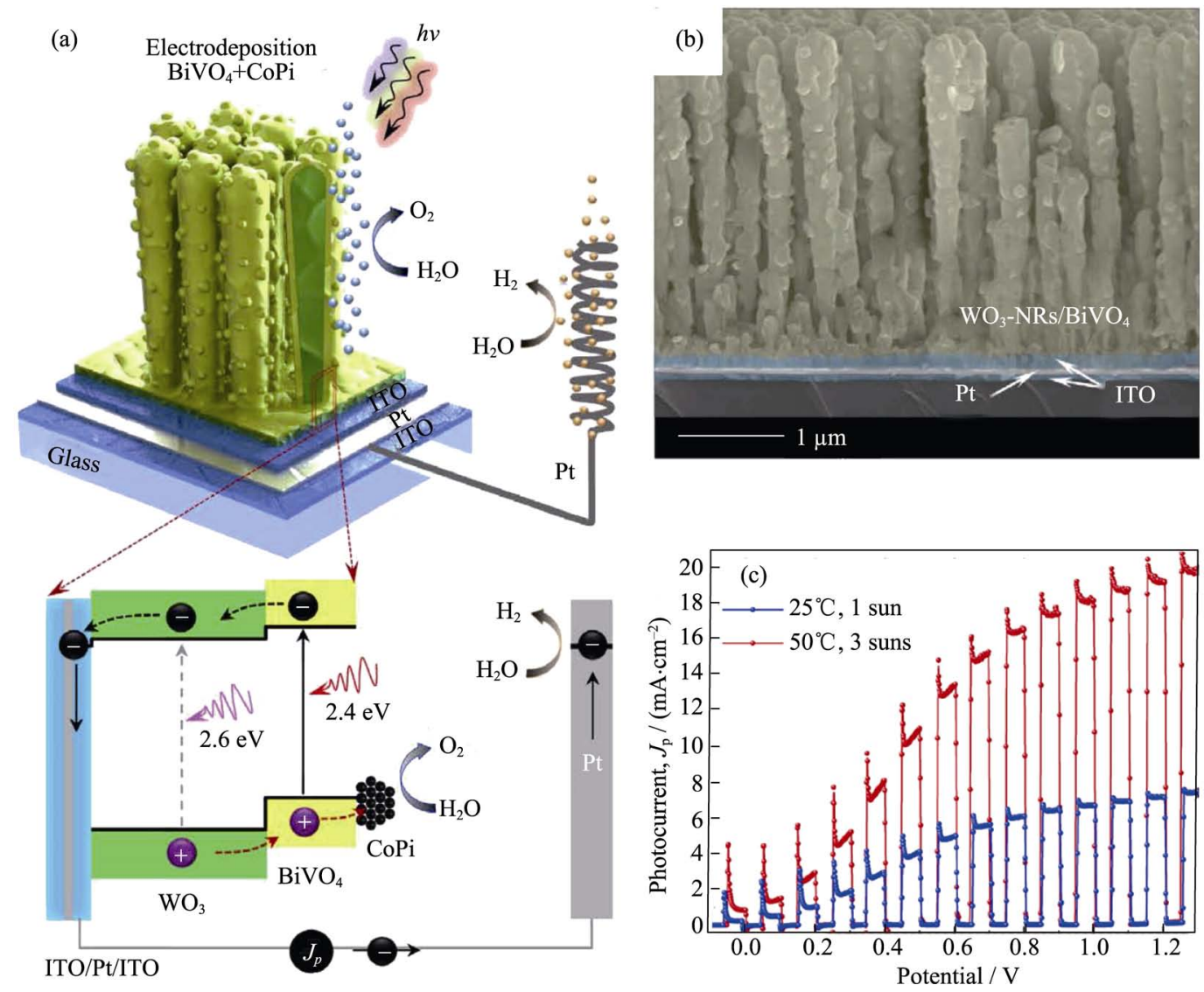

Fig. 12 (a) Schematic of the $\mathrm{WO}_{3} \mathrm{NRs} / \mathrm{BiVO}_{4} / \mathrm{Co}$-Pi junction, the charge transfer and separation in the junction for PEC water splitting; (b) Cross-sectional SEM image of a $\mathrm{WO}_{3} \mathrm{NRs} / \mathrm{BiVO}_{4}$ photoanode; (c) Photocurrent density (vs applied potential) curves of the $\mathrm{WO}_{3} \mathrm{NRs} / \mathrm{BiVO}_{4} / \mathrm{Co}-\mathrm{Pi}$ junction under 1 sun and 3 sun illumination, respectively

Reproduced with permission from Ref. [166]. Copyright 2015 Nature Publishing Group. Distributed under a CC-BY 4.0 license

alignment at their interfaces because the $\mathrm{CB}$ of $\mathrm{TiO}_{2}$ is more negative than $\mathrm{BiVO}_{4}$. Surprisingly, the enhanced PEC performance is attributed to the formation of type II heterojunctions due to the interfacial interactions between $\mathrm{TiO}_{2}$ and $\mathrm{BiVO}_{4}$, evidenced by XPS measurements of the fully assembled nanocomposites in dark and under illumination with a $405 \mathrm{~nm}$ laser ${ }^{[171]}$. In recent years, other Type II $\mathrm{BiVO}_{4}$ based heterojunctions such as Sb-Doped $\mathrm{SnO}_{2} / \mathrm{BiVO}_{4}{ }^{[172]}$, Ta doped $\mathrm{TiO}_{2} / \mathrm{BiVO}_{4}{ }^{[173]}$,

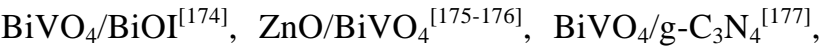
$\mathrm{BiVO}_{4} / \mathrm{CaFe}_{2} \mathrm{O}_{4}{ }^{[178]}$, and $\mathrm{BiVO}_{4} / \mathrm{Co}_{3} \mathrm{O}_{4}{ }^{[179]}$ photoanodes have been developed.

Controlling the $\mathrm{BiVO}_{4}$ photoanodes with highly reactive $\{040\}$ facets can also enhance the PEC performance ${ }^{[180-181]} \cdot \mathrm{BiVO}_{4}$ nanoplate arrays with exposed higher percentage of the lateral $\{040\}$ facets ( $\{040\}$-BVO) were found to be important for PEC water spitting ${ }^{[182]}$. The highly exposed $\{040\}$ facets leads to the higher solar light absorption, higher charge separation efficiency, and longer lifetime of the photogenerated charges, contributing to higher PEC performance. Moreover, the $\{040\}$-BVO photoanode can maintain relatively stable PEC water splitting for over $40 \mathrm{~h}$. By modifying the sur- faces of $\{040\}$-BVO photoanodes with Fe-based layered double hydroxide OECs, higher photocurrent densities can be achieved ${ }^{[183]}$. Generally, a photoanode with more exposed oxidative facets is beneficial for $\mathrm{OER}^{[184]}$. It has been reported that $\mathrm{BiVO}_{4}$ crystals possess reduction functional facets of $\{040\}$ for photogenerated electron accumulation and oxidation functional facets of $\{110\}$ for photogenerated hole accumulation ${ }^{[185-186]}$. Correspondingly, the different orientation of $\{040\}$ and $\{110\}$ also affects the PEC performance of $\mathrm{BiVO}_{4}$ photoanodes, which has been confirmed by a recent study ${ }^{[151]}$. The $\mathrm{BiVO}_{4}$ photoanodes with $\{040\}$ facets grown vertically on the FTO substrates (BVO- $\{040\}-\mathrm{V}$ ) exhibit higher photocurrent densities than the counterpart with $\{040\}$ facets grown parallel to the FTO substrate (BVO- $\{040\}-\mathrm{P}$ ), which is attributed to the exposure of more oxidative facets in the former that provides more reactive sites for OER. Surprisingly, with a mild electrochemical treatment, the BVO-\{040\}-V photoanode with a film thickness of around $1 \mu \mathrm{m}$ exhibits a remarkable photocurrent density of $2.5 \mathrm{~mA} / \mathrm{cm}^{2}$ at $1.23 \mathrm{~V}$ (vs RHE) under AM $1.5 \mathrm{G}$ illumination (Fig. 13(a)-(c)). The partial reduction of $\mathrm{Bi}^{3+}$ and $\mathrm{V}^{5+}$ ions in BVO- $\{040\}-\mathrm{V}$ photoanode that generates 

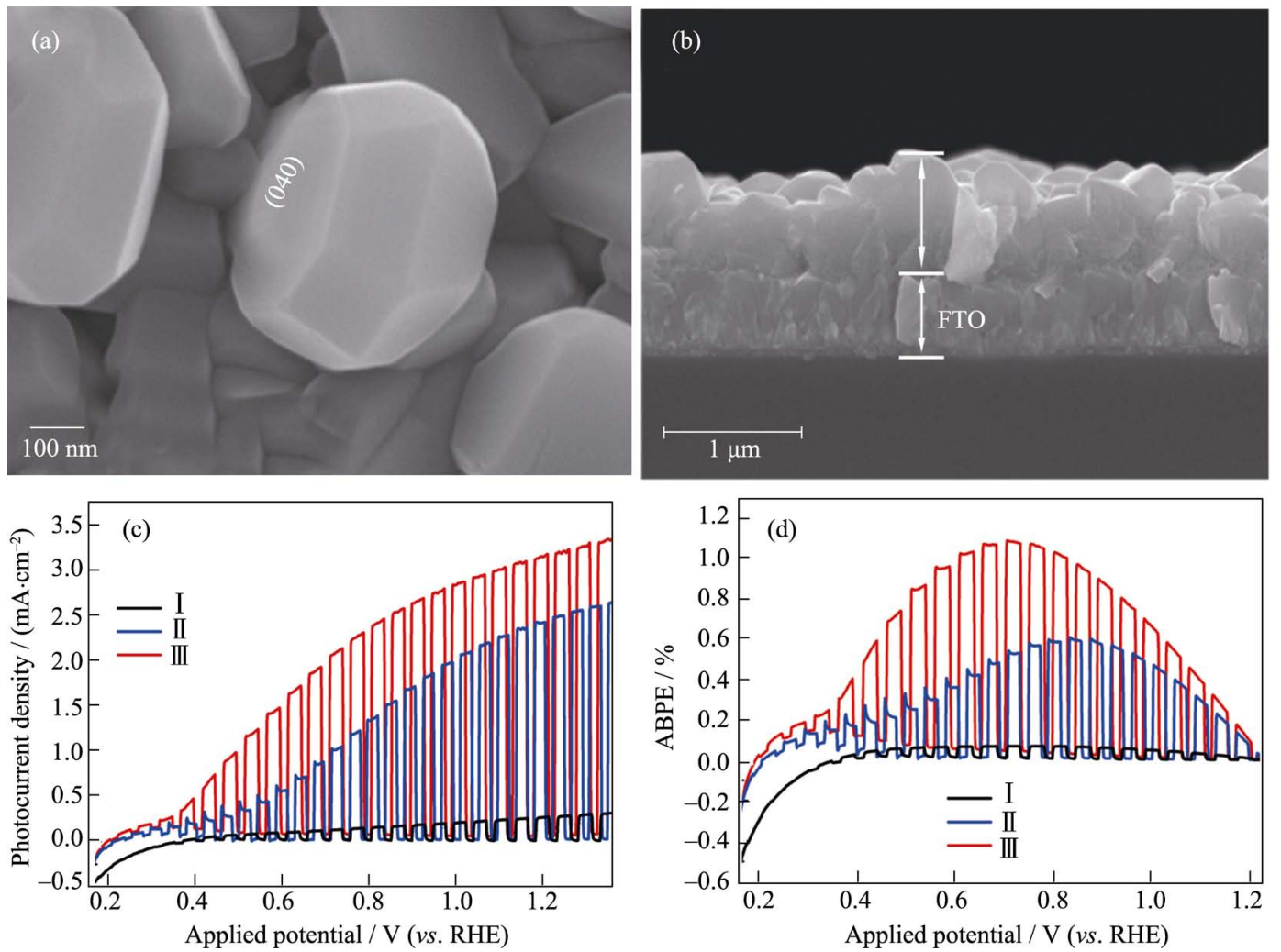

Fig. 13 SEM images of BVO-\{040\}-V: (a) top view and (b) cross-sectional view, (c) photocurrent density vs applied potential curves and (d) the corresponding PEC water splitting efficiency curves of I: BVO-\{040\}-V, II: electrochemically treated

BVO-\{040\}-V, and III: electrochemically treated BVO-\{040\}-V/CoBi photoanodes

Reproduced with permission from Ref. [151]. Copyright 2017 Wiley-VCH Verlag GmbH \& Co. KGaA, Weinheim

oxygen vacancies as shallow donors, which significantly enhances both bulk and surface charge separation, resulting in the drastic improvement of PEC performance. After surface modification with cobalt borate (CoBi) OECs, the photocurrent density can be further enhanced to $3.2 \mathrm{~mA} / \mathrm{cm}^{2}$, with an impressive $1.1 \%$ PEC water splitting efficiency (Fig. 13(c)-(d)). This work provides a new strategy for the design of efficient $\mathrm{BiVO}_{4}$ photoanodes for sustainable solar hydrogen production.

In addition to enhance the photocatalytic activity of $\mathrm{BiVO}_{4}$ photoanodes, long-term stability is another important factor for practical applications. Theoretical calculations have predicted that $\mathrm{BiVO}_{4}$ is resistant to photocorrosion because the oxidation potential of $\mathrm{BiVO}_{4}$ is more positive than the water oxidation potential ${ }^{[187]}$. However, the instability of $\mathrm{BiVO}_{4}$ during PEC water splitting in both near-neutral and alkaline $\mathrm{pH}$ ranges has been observed experimentally ${ }^{\text {[188-191] }}$. Although loading OECs on the surfaces of $\mathrm{BiVO}_{4}$ photoanodes can avoid the direct contact of $\mathrm{BiVO}_{4}$ with electrolyte to improve the stability to some extent, most of the reported stability is only several hours ${ }^{[192-195]}$. Recently, a breakthrough of long-term stability was achieved using a Mo doped $\mathrm{BiVO}_{4}$ photoanode prepared by loading a monolayer of hightemperature treated Mo doped $\mathrm{BiVO}_{4}$ particles on a $\mathrm{Ni}$ contact layer and a subsequent Sn conducting layer ${ }^{[196]}$. The highest PEC photocurrent densities were achieved when the pre-annealed $\left(800^{\circ} \mathrm{C}\right)$ Mo doped $\mathrm{BiVO}_{4}$ particles were ball-milled, followed by the second thermal treatment process at $700^{\circ} \mathrm{C}\left(800^{\circ} \mathrm{C}-\mathrm{BM}-700^{\circ} \mathrm{C}\right)$. Surprisingly, the high-temperature treatment enhances the intrinsic stability of $\mathrm{BiVO}_{4}$ against photocorrosion and chemical corrosion (Fig. 14(a)-(b)). In addition, the Ni layer not only acts as an electrical back contact, but also serves as an ion source to allow in situ self-generation of OECs. Interestingly, the regeneration of OECs is a site-specific process, in which self-generated OECs can be selectively deposited on the sites where catalytic activity decreases due to loss of catalyst. As a result, ultrastable PEC water splitting is achieved for over $1,000 \mathrm{~h}$ at 0.6 V (vs RHE) under AM 1.5 G illumination (Fig. 14(c)).

\section{The applications for unassisted PEC water splitting}

Coupling metal oxide photoanodes with photocathodes or solar cells in tandem to achieve unassisted PEC water splitting (without external bias) is the ultimate goal. In this section, we will briefly summarize the state-of- 

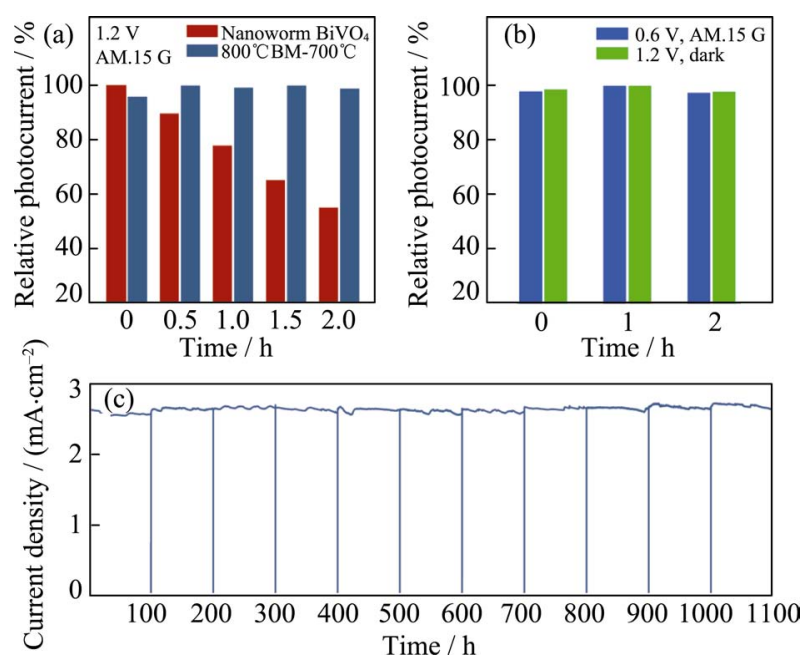

Fig. 14 (a) Photostability measurement of the $800^{\circ} \mathrm{C}-\mathrm{BM}-700^{\circ} \mathrm{C}$ and the previously reported nanoworm $\mathrm{BiVO}_{4}$ photoanodes;

(b) Photostability and electrochemical stability of the $800^{\circ} \mathrm{C}$ $\mathrm{BM}-700^{\circ} \mathrm{C}$ photoanode; (c) Long-term stability measurement of the NiFe-OECs modified $800^{\circ} \mathrm{C}-\mathrm{BM}-700^{\circ} \mathrm{C}$ photoanode at $0.6 \mathrm{~V}$ (vs RHE) under AM $1.5 \mathrm{G}$ illumination

Reproduced with permission from Ref. [196]. Copyright 2016 Nature Publishing Group

the-art progress of unassisted PEC water splitting systems, with the main focus on the utilization of visible light responsive metal oxide photoanodes. Readers may refer to several excellent reviews for more comprehensive information about the unassisted PEC water splitting systems $^{[197-198]}$.

\subsection{PEC tandem systems}

A PEC tandem system is composed of a photoanode and a photocathode with good ohmic contact, forming a Z-scheme junction. Generally, the photoanode is composed of n-type semiconductors, whereas the photocathode is composed of p-type semiconductors. To achieve enhanced performance, OECs and hydrogen evolution cocatalysts (HECs) should be deposited on the photoanode and the photocathode, respectively. As shown in Fig. 15(a), under light illumination, photogenerated elec- trons in the $\mathrm{CB}$ of the photoanode will recombine with the holes in the VB of the photocathode, leaving holes in the VB of the photoanode for OER while electrons in the CB of the photocathode for HER. The photoanode and photocathode can be connected with a conductive metal wire to form a wire configuration or a transparent conductive material to form a wireless configuration. Moreover, the photoanode and photocathode can be assembled side-by-side to form a parallel illumination mode (Mode P, Fig. 15(b)), or in series to form a tandem illumination mode (Mode T, Fig. 15(c)). Both photoanode and photocathode are exposed to the full solar spectrum in Mode P. Thus, transparency and bandgap difference are not required for the photoelectrodes. While in Mode T, the front photoelectrode should be transparent with larger bandgap, so that more light with lower energy penetrating through the front photoelectrode can be utilized by the back photoelectrode with smaller bandgap. Due to the mismatch of band edge positions of most photoanode and photocathode materials, very few PEC tandem systems can be achieved ${ }^{[197]}$.

With the low onset potential, $\mathrm{BiVO}_{4}$ photoanodes are good candidates used in PEC tandem systems. By coupling a $\mathrm{W}$ doped $\mathrm{BiVO}_{4} / \mathrm{Co}$-Pi photoanode with a $\mathrm{Cu}_{2} \mathrm{O} / \mathrm{Al}: \mathrm{ZnO} / \mathrm{TiO}_{2} / \mathrm{RuO}_{x}$ photocathode to form a Mode $\mathrm{T}$ wired configuration, a STH efficiency of $0.5 \%$ was achieved $^{[199]}$. However, the abstained STH efficiency is still much lower than the theoretical maximum of $8 \%$ for this system based on the known band gap energies and band edge positions. Owing to the low onset slopes (Fill Factors) of both photoanode and photocathode, less than $1 \mathrm{~mA} / \mathrm{cm}^{2}$ of photocurrent density can be achieved at the intersect of the $J-V$ curves (Fig. 16(a)). In another case, a $\mathrm{Pt} / \mathrm{In}_{2} \mathrm{~S}_{3} / \mathrm{CdS} / \mathrm{Cu}_{2} \mathrm{ZnSnS}_{4}$ photocathode was connected with a $\mathrm{FeOOH} / \mathrm{BiVO}_{4}$ photoanode through a conducting wire for unassisted PEC water splitting, achieving a STH efficiency of $0.28 \%{ }^{[200]}$. A wireless artificial leaf composed of free-standing $\mathrm{BiVO}_{4}$ and $\mathrm{Ru} / \mathrm{Rh}-\mathrm{SrTiO}_{3}$ nanowires was fabricated using solution synthesis and
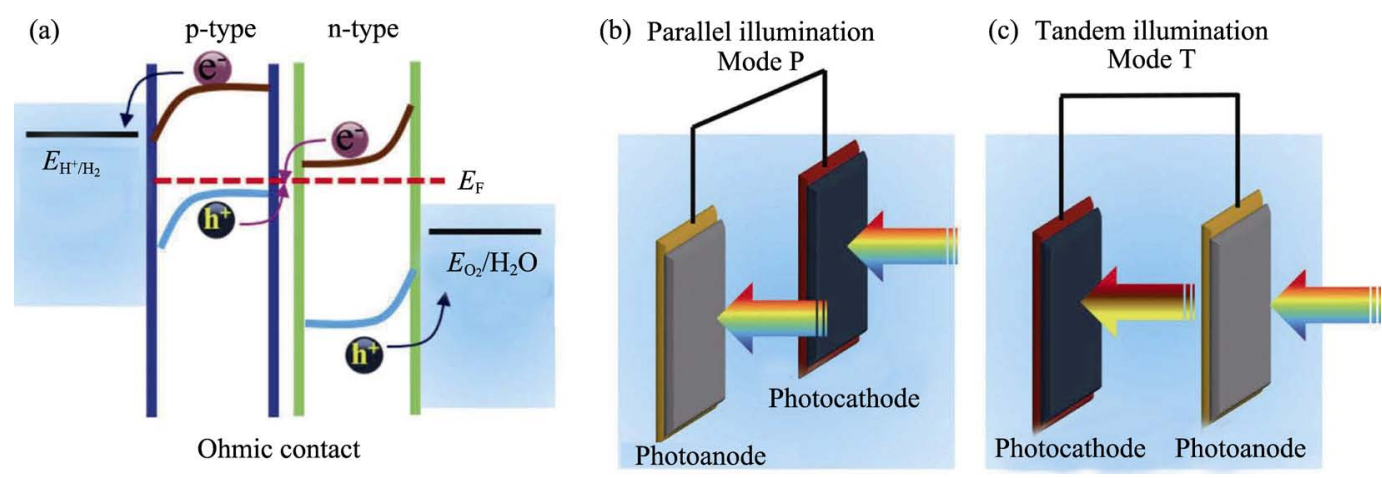

Fig. 15 (a) Mechanism of a PEC tandem system with Ohmic contact, a schematic of the wired PEC tandem system in (b) a parallel illumination mode (Mode P) and (c) a tandem illumination mode (Mode T) Reproduced with permission from Ref. [197]. Copyright 2016 Wiley-VCH Verlag GmbH \& Co. KGaA, Weinheim 

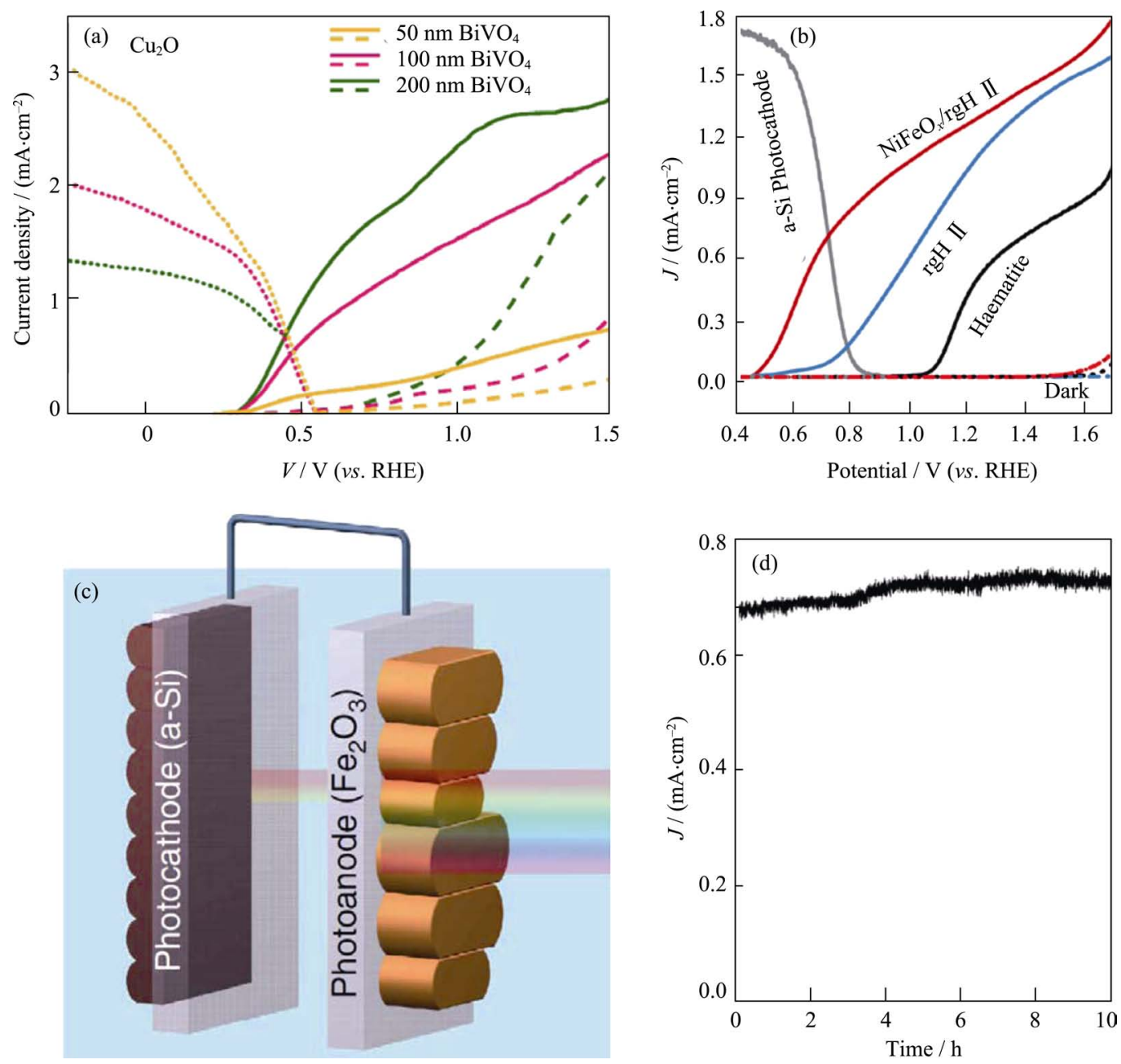

Fig. 16 (a) Current density-voltage $(\mathrm{J}-\mathrm{V})$ curves of the $\mathrm{BiVO}_{4}$ photoanodes with (solid lines) and without (dashed lines) Co-Pi OECs under AM $1.5 \mathrm{G}$ illumination. The $|J|-V$ curves of the $\mathrm{Cu}_{2} \mathrm{O}$ photocathode is measured with the coverage of the corresponding $\mathrm{BiVO}_{4}$ photoanode (dotted line with the same colour). Reproduced with permission from Ref. [199]. Copyright 2014 American Chemical Society. (b) $J-V$ curves of various $\alpha-\mathrm{Fe}_{2} \mathrm{O}_{3}$ photoanodes. The $|J|-V$ curve of the Si photocathode is measured behind the $\alpha-\mathrm{Fe}_{2} \mathrm{O}_{3}$ photoanode. (c) Schematic of overall unassisted water splitting by $\alpha-\mathrm{Fe}_{2} \mathrm{O}_{3}$ photoanode and amorphous $\mathrm{Si}$ photocathode in wired Mode T. (d) Photocurrent stability measurement of the PEC tandem system in (c). Reproduced with permission from Ref.

[202]. Copyright 2015 Nature Publishing Group. Distributed under a CC-BY 4.0 license

vacuum filtration, which can achieve spontaneous overall water splitting ${ }^{[201]}$. Nevertheless, the STH efficiency is only $0.0017 \%$. A new record of $0.91 \%$ STH efficiency was obtained in a PEC tandem system composed of a modified $\alpha-\mathrm{Fe}_{2} \mathrm{O}_{3}$ photoanode and a Si photocathode ${ }^{[202]}$. A facile re-growth strategy is developed to effectively reduce the surface disorders on $\alpha-\mathrm{Fe}_{2} \mathrm{O}_{3}$ photoanodes, which greatly shifts the onset potential to $0.45 \mathrm{~V}$ (vs RHE). Further modifying the surfaces with $\mathrm{NiFeO}_{x}$ OECs, the fill factor of the $\alpha-\mathrm{Fe}_{2} \mathrm{O}_{3}$ photoanode can be significantly improved (Fig. 16(b)). In addition, the wired Mode $\mathrm{T}$ configuration can generate stable photocurrent densities without external bias for $10 \mathrm{~h}$ (Fig. 16(c) and 16(d)).

Theoretically, a maximum STH efficiency of 29.7\% can be achieved for PEC tandem systems ${ }^{[203]}$. However, the real STH efficiencies of PEC tandem systems are still less than $1 \%$ using earth abundant metal oxide photo- anodes $^{[202]}$, due to the lack of photoanode and photocathode materials with appropriate bandgap and matchable band edge positions to deliver high enough operated photocurrent densities.

\subsection{PEC/PV tandem systems}

Alternatively, coupling visible light responsive photoanodes with photovoltaic (PV) devices to form PEC/PV tandem systems is easier to achieve unassisted PEC water splitting. The PV devices can provide high enough photovoltage for the photoanode, so that the PEC/PV tandem system can be driven by only sunlight. In this regard, the harsh requirements for the PEC tandem systems can be alleviated in the PEC/PV tandem systems. However, it is important to keep the balance of solar light absorption between the PEC and PV cells to achieve optimized STH efficiencies. On the other hand, PV devices are generally unstable in aqueous solutions, so the 
protection of PV devices in the PEC/PV tandem systems should also be considered. Compared to the triple-junction amorphous silicon ${ }^{[204]}$ and III-V multi-junction ${ }^{[205-206]}$ PV devices for direct water splitting, the utilization of earth-abundant metal oxide photoanodes in the PEC/PV tandem systems can reduce the cost and device complexity as well.

An early work demonstrated PEC/PV tandem devices with a $\mathrm{WO}_{3}$ or $\alpha-\mathrm{Fe}_{2} \mathrm{O}_{3}$ photoanode connected with a dyesensitized solar cell (DSSC) ${ }^{[207]}$. As shown in Fig. 17(a) and $17(\mathrm{~b})$, light is incident on the $\mathrm{WO}_{3}$ or $\alpha-\mathrm{Fe}_{2} \mathrm{O}_{3}$ photoanode before the underlying DSSC. Both photoanode and DSSC are excited to generate electron-hole pairs and the electrons in the photoanode will recombine with the holes in the DSSC, leaving holes in the photoanode for OER while electrons in the DSSC for HER, similar to the Z-scheme mechanism in PEC tandem systems (Fig. 17(c)). Therefore, the photoanode should be transparent with a bandgap larger than the light absorber in the DSSC, so that solar light with energy lower than the bandgap of the photoanode can efficiently penetrate through the photoanode to be absorbed by DSSC. Modifying the photoanode to achieve higher photocurrent densities, in particular at the onset potential will significantly enhance the STH efficiency for the whole system. $\mathrm{A} \mathrm{WO}_{3} / \mathrm{BiVO}_{4}$ heterojunction photoanode decorated with dual-layer $\mathrm{FeOOH} / \mathrm{NiOOH}$ OECs led to a STH efficiency of $5.7 \%$ when coupled with a DSSC ${ }^{[208]}$. By further introducing a hybrid conductive distributed Bragg reflector on the back side of the transparent
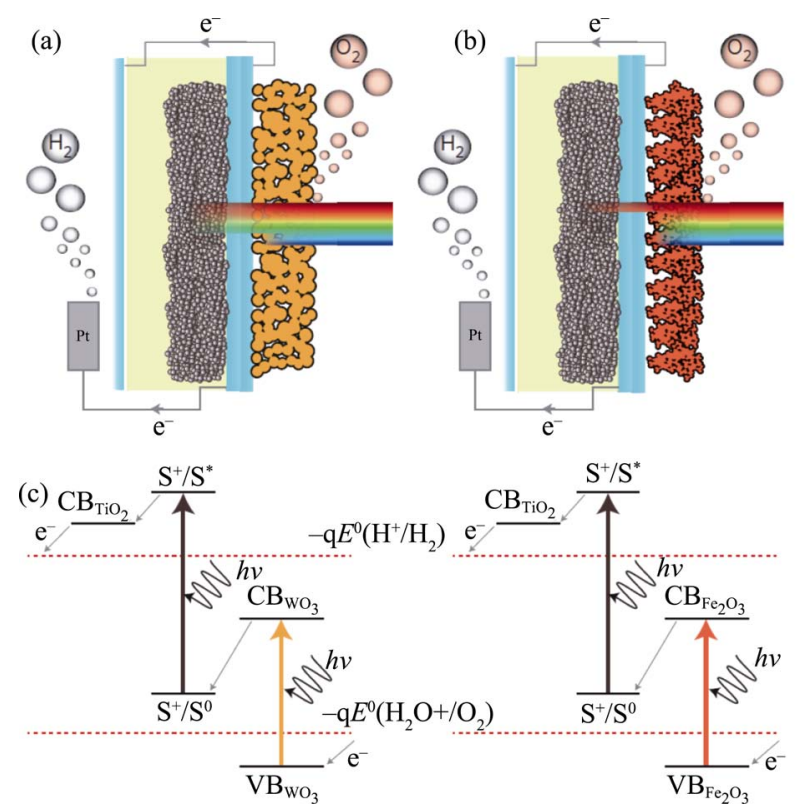

Fig. 17 General schemes of a $\mathrm{WO}_{3} / \mathrm{DSSC}$ tandem system (a) and $\mathrm{Fe}_{2} \mathrm{O}_{3}$ /DSSC tandem system (b); Working mechanism of the $\mathrm{WO}_{3} /$ DSSC and $\mathrm{Fe}_{2} \mathrm{O}_{3}$ /DSSC tandem systems (c)

Reproduced with permission from Ref. [207]. Copyright 2012 Nature Publishing Group conducting substrate for the front photoanode to enhance solar light utilization, an impressive STH efficiency of $7.1 \%$ was achieved ${ }^{[209]}$.

In addition, silicon cells and III-V multi-junction cells have also been used in the PEC/PV tandem systems. Due to the low open circuit potential, at least double junction of silicon cells or III-V multi-junction cells are generally required to provide satisfied photovoltage for the photoanode. Using Mo doped $\mathrm{BiVO}_{4}$ modified by FeOOH OECs as the photoanode and triple-junction $\mathrm{Si}$ solar cell as the photocathode, a STH efficiency of $2.5 \%$ was achieved in the Mode $\mathrm{P}$ configuration ${ }^{[210]}$. Higher STH efficiencies can be achieved by the modification of the $\mathrm{BiVO}_{4}$ photoanode. For example, the gradient doped $\mathrm{BiVO}_{4} / \mathrm{Co}-\mathrm{Pi}$ photoanode/double junction Si solar cell tandem system can achieve $4.9 \%$ STH efficiency ${ }^{[147]}$, whereas the $\mathrm{WO}_{3} / \mathrm{BiVO}_{4} / \mathrm{CoPi}$ photoanode/double-junction GaAs/InGaAsP solar cell tandem system generate a high STH efficiency of $8.1 \%{ }^{[166]}$. Recently, transparent $\mathrm{BiVO}_{4}$ and $\alpha-\mathrm{Fe}_{2} \mathrm{O}_{3}$ dual photoanodes were developed to extend the light absorption range up to $610 \mathrm{~nm}$, which can achieve a STH efficiency of $7.7 \%$ when coupled with two crystalline Si (c-Si) solar cells (Fig. 18) ${ }^{[211]}$.

The rapid development of perovskite solar cells (PSCs) may open up new opportunities in the PEC/PV tandem systems. Due to the high open circuit potential (0.9-1.5 V), tuneable bandgap and cost-effective properties, PSCs have attracted increasing attention in PEC/PV tandem systems. Generally, only one PSC is required for the $\mathrm{PEC} / \mathrm{PV}$ tandem systems, which can reduce the complexity of the device and decrease the cost as well. However, PSCs cannot survive in aqueous solutions. Thus, avoiding the direct contact of PSCs with water should be considered when designing this kind of devices. $\mathrm{A} \mathrm{BiVO}_{4} /$ PSC device with wired configuration was designed by soaking the $\mathrm{BiVO}_{4}$ photoanode in the electrolyte solution while keeping the PSC in the air (Fig. 19(a)) with light illumination from the $\mathrm{BiVO}_{4}$ photoanode, which can achieve a STH efficiency of $2.5 \%{ }^{[212]}$. Another different design of wired $\mathrm{BiVO}_{4} / \mathrm{PSC}$ system was reported using a beam filter to separate the light into different regions, where the light with $\lambda<515 \mathrm{~nm}$ can pass through the beam filter for $\mathrm{BiVO}_{4}$ photoanodes in aqueous solution while the light with $\lambda>515 \mathrm{~nm}$ will be reflected to PSC in the air (Fig. 19(b) $)^{[213]}$. The system can generate a stable photocurrent density of $5.01 \mathrm{~mA} / \mathrm{cm}^{2}$ for $10 \mathrm{~h}$ (Fig. 19(d)), corresponding to a STH efficiency of $6.2 \%$. The efficient photoanode alone can achieve a photocurrent density of (5.82 \pm 0.36$) \mathrm{mA} / \mathrm{cm}^{2}$ at $1.23 \mathrm{~V}$ ( $v s$ RHE) under AM 1.5 G illumination, which is attributed to the engineered cone- shaped nanostructures as substrates for the deposition of nanoporous Mo-doped $\mathrm{BiVO}_{4}$. Compared to a flat substrate, the nanocone substrate not only can 
(a)

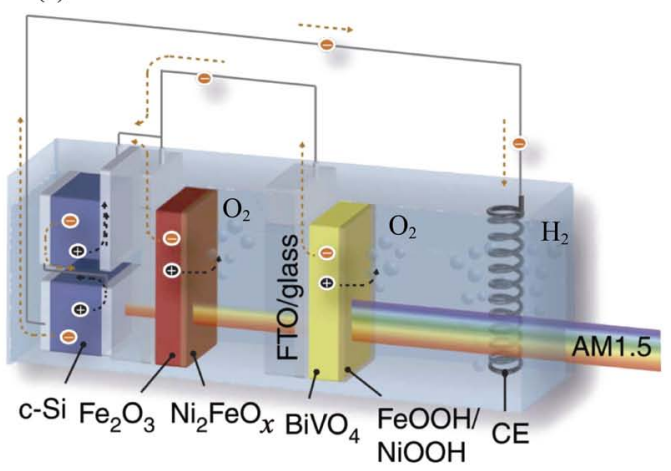

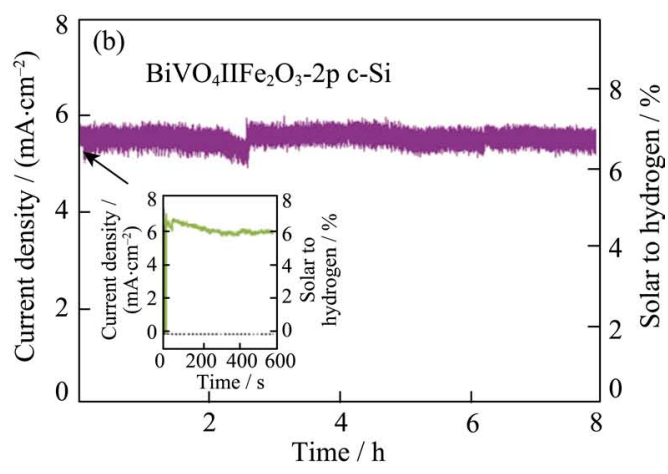

Fig. 18 (a) Scheme of a PEC/PV tandem cell with modified $\mathrm{BiVO}_{4} / \alpha-\mathrm{Fe}_{2} \mathrm{O}_{3}$ dual photoanodes and two parallel-connected c-Si cells;

(b) Stability of unassisted water splitting with inset showing: data recorded for short term illumination Reproduced with permission from Ref. [211]. Copyright 2016 Nature Publishing Group. Distributed under a CC-BY 4.0 license

(a)

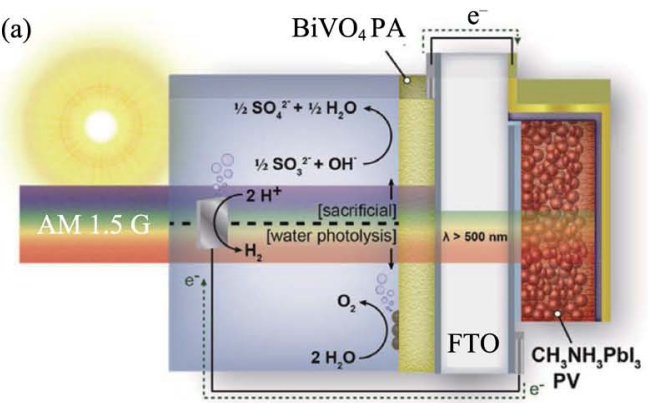

(c)

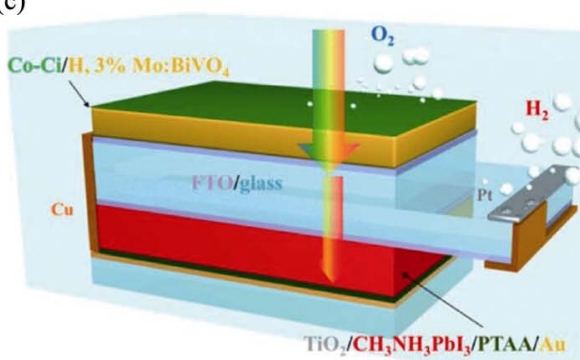

(b)
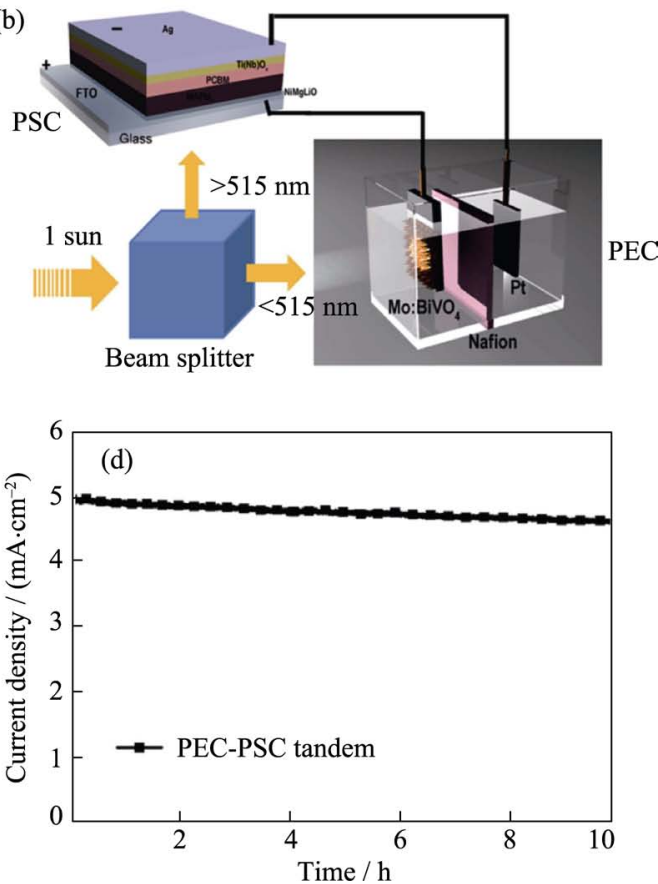

Fig. 19 Schematics of (a) $\mathrm{BiVO}_{4} / \mathrm{PSC}$ tandem device with PSC behind the $\mathrm{BiVO}_{4}$ photoanode in air,

(b) $\mathrm{BiVO}_{4} / \mathrm{PSC}$ tandem device with a beam splitter, and (c) wireless artificial leaf of $\mathrm{BiVO}_{4} / \mathrm{PSC}$ tandem device,

(d) stability measurement of the $\mathrm{BiVO}_{4} / \mathrm{PSC}$ tandem device in (b)

Reproduced with permission from Ref. [212-214]. Copyright 2015 American Chemical Society. Distributed under an ACS AuthorChoice License. Copyright 2016 American Association for the Advancement of Science. Distributed under a CC BY-NC 4.0 license

Copyright 2015 American Chemical Society

maintain the high charge separation efficiency of thicker $\mathrm{BiVO}_{4}$ films, but also enhances the light absorption ability by multiple light scattering in the nanocone structure. On the other hand, a wireless artificial leaf was prepared using a modified $\mathrm{BiVO}_{4}$ photoanode and a sealed PSC, which can be immerged in the electrolyte solution directly (Fig. 19(c) $)^{[214]}$. Stable overall water splitting can be achieved for $12 \mathrm{~h}$, with a STH efficiency of 3.0\%.

The STH efficiency of the PEC/PV tandem systems is mainly determined by the performance of the photoanode. In particular, it is important to improve the photocurrent densities of the photoanodes at the potential range of
0.6-0.7 $\mathrm{V}$ that matches the operating potentials of most solar cells ${ }^{[172]}$. Moreover, transparency is also important to allow the bottom solar cells to absorb enough light. However, it is challenging to keep the balance of transparency and high photocurrent densities of a photoanode. For example, reducing the thickness of a photoanode can keep good transparency, but the photocurrent densities are also reduced due to the decrease of light harvesting. To achieve high performance in a PEC/PV tandem system, both PEC performance and transparency of the photoanode should be carefully tailored. For practical applications, the cost should also been considered. Al- 
though the rapid development of PSCs may provide cheaper solar cells for the PEC/PV tandem systems, it is very challenging to achieve ultra-stable PSCs in aqueous solutions.

\section{Conclusion and outlook}

PEC water splitting is an important technique for solar hydrogen production, which is promising to address the potential energy crisis with less-adverse impact on climate change. Although a hybrid system composed of two polymer electrolyte membrane electrolysers in series with one InGaP/GaAs/GaInNAsSb triple-junction solar cell can achieve the world record efficiency of $\sim 30 \%$ for water splitting ${ }^{[215]}$, the use of III-V multi-junction PV and noble metal are prohibitively expensive. For low-cost PEC water splitting systems, the STH efficiencies are still too low to achieve the $10 \%$ target for practical applications. Compared to photocathodes for HER, it is more challenging to develop efficient and stable photoanodes for OER due to the harsh oxidation environment and four-electron process that generally cause photocorrosion and severe charge recombination. Compared to metal sulphides and nitrides that are vulnerable in a strong oxidation environment, metal oxides are much more stable during PEC water splitting. In order to achieve high STH efficiencies, the first requirement for metal oxide photoanodes should possess narrow bandgap for visible light harvesting. Therefore, the development of robust and efficient visible light responsive photoanodes is of great significance for PEC water splitting. In this review, we have summarized the state-of-the-art progresses of visible light responsive metal oxide photoanodes with a focus on the rational design of $\mathrm{WO}_{3}$, $\alpha-\mathrm{Fe}_{2} \mathrm{O}_{3}$, and $\mathrm{BiVO}_{4}$ photoanodes toward efficient PEC water splitting. Moreover, their applications in unassisted PEC water splitting by coupling with photocathodes or solar cells have also been concisely introduced. In particular, we focus on the working mechanisms and the characteristics of various unassisted PEC water splitting systems using visible light responsive photoanodes.

In the past decades, even though numerous achievements have been obtained on visible light responsive photoanodes, it is still challenging to develop an efficient photoanode for unassisted water splitting with 10\% STH efficiencies in a PEC tandem system. By coupling with solar cells, higher STH efficiencies can be achieved. However, the complexity and cost of the whole device also increase. To achieve high STH efficiencies in an unassisted PEC tandem system, it is important to greatly reduce the onset potential and significantly increase the photocurrent density at the onset potential of a photo- anode. Strategies such as nanostructural control, doping, heterojunction construction, cocatalyst deposition, plasmonic enhancement, crystal facet engineering can overcome the intrinsic drawbacks of $\mathrm{WO}_{3}, \alpha-\mathrm{Fe}_{2} \mathrm{O}_{3}$, and $\mathrm{BiVO}_{4}$ photoanodes to some extent. However, even the combination of the above mentioned strategies still cannot achieve high photocurrent densities at a desirable low onset potential of these photoanodes. Most of the researches on photoanodes only focus on the photocurrent densities at the water oxidation potential of $1.23 \mathrm{~V}$ ( $v s$ RHE). In the PEC/PV tandem systems, the operating potential of the PV device is at $0.6-0.7 \mathrm{~V}$, while the operating potential in the PEC tandem system is even lower. Thus, more attention should be paid to improve the photocurrent densities of a photoanode at lower potentials. In addition to $\mathrm{WO}_{3}, \alpha-\mathrm{Fe}_{2} \mathrm{O}_{3}$, and $\mathrm{BiVO}_{4}$ photoanodes, other metal oxide photoanodes such as $\mathrm{CuWO}_{4}{ }^{[216]}, \mathrm{Bi}_{2} \mathrm{WO}_{6}{ }^{[217]}, \mathrm{TiFe}_{2} \mathrm{O}_{5}{ }^{[218]}, \mathrm{Bi}_{2} \mathrm{Mo}_{3} \mathrm{O}_{12}{ }^{[217]}$, $\mathrm{CuV}_{2} \mathrm{O}_{6}{ }^{[219-220]}, \quad \mathrm{Cu}_{2} \mathrm{~V}_{2} \mathrm{O}_{7}^{[219-220]}, \quad \mathrm{Cu}_{3} \mathrm{~V}_{2} \mathrm{O}_{8}{ }^{[221]}$, and $\mathrm{FeVO}_{4}{ }^{[222-223]}$ have been developed in recent years. However, most of the reported photocurrent densities of these photoanodes are very low $\left(<1 \mathrm{~mA} / \mathrm{cm}^{2}\right)$. The conventional strategies may not work well for these materials. The exploration of other efficient strategies to achieve high photocurrent densities are required. Meanwhile, we should not lose the patience in exploring new materials. If thinking "out of the box" about PEC water splitting, maybe the development of other research fields can open up new opportunities for PEC water splitting.

\section{Acknowledgements}

The authors would like to acknowledge the financial support from Australian Research Council through its DP and FF programs. S. Wang acknowledges the support from Australian Government Research Training Program and UQ Centennial Scholarships.

\section{References:}

[1] KITOUS A, KERAMIDAS K, VANDYCK T, et al. GECO 2016: Global Energy and Climate Outlook: Road from Paris: Impact of Climate Policies on Global Energy Markets in the Context of the UNFCCC Paris Agreement, EUR 27952 EN, Publications Office of the European Union: KITOUS A, 2016. 25-83. DOI: $10.2790 / 89230$.

[2] LEWIS N S, NOCERA D G. Powering the planet: chemical challenges in solar energy utilization. Proc. Natl. Acad. Sci. U. S. A., 2006, 103(43): 15729-15735.

[3] GRATZEL M. Photoelectrochemical cells. Nature, 2001, 414(6861): 338-344.

[4] FUJISHIMA A, HONDA K. Electrochemical photolysis of water at a semiconductor electrode. Nature, 1972, 238(5358): 37-38.

[5] FAUNCE T, STYRING S, WASIELEWSKI M R, et al. Artificial 
photosynthesis as a frontier technology for energy sustainability. Energy Environ. Sci., 2013, 6(4): 1074-1076.

[6] YANG Y, WANG S, LI Y, et al. Strategies for efficient solar water splitting using carbon nitride. Chem. Asian J., 2017, 12(13): 1421-1434.

[7] CHEN J, ZHAO D, DIAO Z, et al. Ferrites boosting photocatalytic hydrogen evolution over graphitic carbon nitride: a case study of (Co, Ni) $\mathrm{Fe}_{2} \mathrm{O}_{4}$ modification. Sci. Bull., 2016, 61(4): 292-301.

[8] HAN Y, ZHANG L, WANG Y, et al. Photoelectrocatalytic activity of an ordered and vertically aligned $\mathrm{TiO}_{2}$ nanorod array/BDD heterojunction electrode. Sci. Bull., 2017, 62(9): 619-625.

[9] LIM M, ZHOU Y, WANG L Z, et al. Development and potential of new generation photocatalytic systems for air pollution abatement: an overview. Asia-Pac. J. Chem. Eng., 2009, 4(4): 387-402.

[10] ZHANG W, ZOU L D, WANG L Z. Photocatalytic $\mathrm{TiO}_{2} /$ adsorbent nanocomposites prepared via wet chemical impregnation for wastewater treatment: a review. Appl. Catal. a-Gen., 2009, 371(1/2): $1-9$.

[11] GARCIA-SEGURA S, BRILLAS E. Applied photoelectrocatalysis on the degradation of organic pollutants in wastewaters. $J$. Photochem. Photobiol. C, 2017, 31: 1-35.

[12] LIU J, HAN L, MA H, et al. Template-free synthesis of carbon doped $\mathrm{TiO}_{2}$ mesoporous microplates for enhanced visible light photodegradation. Sci. Bull., 2016, 61(19): 1543-1550.

[13] KUMAR B, LLORENTE M, FROEHLICH J, et al. Photochemi$\mathrm{cal}$ and photoelectrochemical reduction of $\mathrm{CO}_{2}$. Annu. Rev. Phys. Chem., 2012, 63: 541-569.

[14] RONGE J, BOSSEREZ T, MARTEL D, et al. Monolithic cells for solar fuels. Chem. Soc. Rev., 2014, 43(23): 7963-7981.

[15] SUN Z, WANG S, LI Q, et al. Enriching $\mathrm{CO}_{2}$ activation sites on graphitic carbon nitride with simultaneous introduction of electrontransfer promoters for superior photocatalytic $\mathrm{CO}_{2}$-to-fuel conversion. Adv. Sustainable Syst., 2017, 1(3/4): 1700003.

[16] MEI B, MUL G, SEGER B. Beyond water splitting: efficiencies of photo-electrochemical devices producing hydrogen and valuable oxidation products. Adv. Sustainable Syst., 2017, 1(1/2): 1600035.

[17] ZONG X, HAN J, SEGER B, et al. An integrated photoelectrochemical-chemical loop for solar-driven overall splitting of hydrogen sulfide. Angew. Chem. Int. Ed., 2014, 53(17): 4399-4403.

[18] ZONG X, CHEN H J, SEGER B, et al. Selective production of hydrogen peroxide and oxidation of hydrogen sulfide in an unbiased solar photoelectrochemical cell. Energy Environ. Sci., 2014, 7(10): 3347-3351.

[19] SKUBI K L, BLUM T R, YOON T P. Dual catalysis strategies in photochemical synthesis. Chem. Rev., 2016, 116(17): 1003510074.

[20] KONDRATENKO E V, MUL G, BALTRUSAITIS J, et al. Status and perspectives of $\mathrm{CO}_{2}$ conversion into fuels and chemicals by catalytic, photocatalytic and electrocatalytic processes. Energy Environ. Sci., 2013, 6(11): 3112-3135.

[21] FAGNONI M, DONDI D, RAVELLI D, et al. Photocatalysis for the formation of the C-C bond. Chem. Rev., 2007, 107(6): 2725-2756.

[22] WANG S, YUN J H, WANG L. Nanostructured semiconductors for bifunctional photocatalytic and photoelectrochemical energy conversion. Semicond. Semimetals, 2017, 97: 315-347.

[23] HISATOMI T, KUBOTA J, DOMEN K. Recent advances in semiconductors for photocatalytic and photoelectrochemical water splitting. Chem. Soc. Rev., 2014, 43(22): 7520-7535.

[24] PREVOT M S, SIVULA K. Photoelectrochemical tandem cells for solar water splitting. J. Phys. Chem. C, 2013, 117(35):
$17879-17893$.

[25] QU Y, DUAN X. Progress, challenge and perspective of heterogeneous photocatalysts. Chem. Soc. Rev., 2013, 42(7): 2568-2580.

[26] GAN J, LU X, TONG Y. Towards highly efficient photoanodes: boosting sunlight-driven semiconductor nanomaterials for water oxidation. Nanoscale, 2014, 6(13): 7142-7164.

[27] GANNOUNI M, BEN ASSAKER I, CHTOUROU R. Photoelectrochemical cell based on n-CuIn ${ }_{5} \mathrm{~S}_{8}$ film as photoanodes for photocatalytic water splitting. Int. J. Hydrogen Energy, 2015, 40(23): 7252-7259.

[28] XIA Z M, ZHOU X M, LI J, et al. Protection strategy for improved catalytic stability of silicon photoanodes for water oxidation. Sci. Bull., 2015, 60(16): 1395-1402.

[29] LICHTERMAN M F, SUN K, HU S, et al. Protection of inorganic semiconductors for sustained, efficient photoelectrochemical water oxidation. Catal. Today, 2016, 262: 11-23.

[30] WANG L, SASAKI T. Titanium oxide nanosheets: graphene analogues with versatile functionalities. Chem. Rev., 2014, 114(19): 9455-9486.

[31] MA Y, WANG X, JIA Y, et al. Titanium dioxide-based nanomaterials for photocatalytic fuel generations. Chem. Rev., 2014, 114(19): 9987-10043.

[32] LIU Y, TIAN L, TAN X, et al. Synthesis, properties, and applications of black titanium dioxide nanomaterials. Sci. Bull., 2017, 62(6): 431-441.

[33] AROUTIOUNIAN V M, ARAKELYAN V M, SHAHNAZARYAN G E. Metal oxide photoelectrodes for hydrogen generation using solar radiation-driven water splitting. Sol. Energy, 2005, 78(5): 581-592.

[34] ZONG X, THAWEESAK S, XU H, et al. A scalable colloidal approach to prepare hematite films for efficient solar water splitting. Phys. Chem. Chem. Phys., 2013, 15(29): 12314-12321.

[35] ZHENG X L, SONG J P, LING T, et al. Strongly coupled nafion molecules and ordered porous CdS networks for enhanced visiblelight photoelectrochemical hydrogen evolution. Adv. Mater., 2016, 28(24): 4935-4942.

[36] WANG G, YANG X, QIAN F, et al. Double-sided CdS and CdSe quantum dot co-sensitized $\mathrm{ZnO}$ nanowire arrays for photoelectrochemical hydrogen generation. Nano Lett., 2010, 10(3): 10881092.

[37] CAO S Y, YAN X Q, KANG Z, et al. Band alignment engineering for improved performance and stability of $\mathrm{ZnFe}_{2} \mathrm{O}_{4}$ modified $\mathrm{CdS} / \mathrm{ZnO}$ nanostructured photoanode for PEC water splitting. Nano Energy, 2016, 24: 25-31.

[38] ZHONG Y J, LI Z S, ZHAO X, et al. Enhanced water-splitting performance of perovskite $\mathrm{SrTaO}_{2} \mathrm{~N}$ photoanode film through ameliorating interparticle charge transport. Adv. Funct. Mater., 2016, 26(39): 7156-7163.

[39] XIAO M, WANG S, THAWEESAK S, et al. Tantalum (oxy)nitride: narrow bandgap photocatalysts for solar hydrogen generation. Engineering, 2017, 3(3): 365-378.

[40] ZHEN C, CHEN R Z, WANG L Z, et al. Tantalum (oxy)nitride based photoanodes for solar-driven water oxidation. J. Mater. Chem. A, 2016, 4(8): 2783-2800.

[41] XIAO M, LUO B, LYU M, et al. Single-crystalline nanomesh tantalum nitride photocatalyst with improved hydrogen-evolving performance. Adv. Energy Mater., 2017, DOI: 10.1002/aenm. 201701605.

[42] SUN K, SHEN S, LIANG Y, et al. Enabling silicon for solar-fuel production. Chem. Rev., 2014, 114(17): 8662-8719.

[43] WANG T, GONG J. Single-crystal semiconductors with narrow band gaps for solar water splitting. Angew. Chem. Int. Ed., 2015, 
54(37): 10718-10732.

[44] BAE D, SEGER B, VESBORG P C, et al. Strategies for stable water splitting via protected photoelectrodes. Chem. Soc. Rev., 2017, 46(7): 1933-1954.

[45] LIU C, DASGUPTA N P, YANG P. Semiconductor nanowires for artificial photosynthesis. Chem. Mater., 2014, 26(1): 415-422.

[46] LI H, ZHOU Y, TU W, et al. State-of-the-art progress in diverse heterostructured photocatalysts toward promoting photocatalytic performance. Adv. Funct. Mater., 2015, 25(7): 998-1013.

[47] WANG H, ZHANG L, CHEN Z, et al. Semiconductor heterojunction photocatalysts: design, construction, and photocatalytic performances. Chem. Soc. Rev., 2014, 43(15): 5234-5244.

[48] MONIZ S J A, SHEVLIN S A, MARTIN D J, et al. Visible-light driven heterojunction photocatalysts for water splitting - a critical review. Energy Environ. Sci., 2015, 8(3): 731-759.

[49] KUDO A, MISEKI Y. Heterogeneous photocatalyst materials for water splitting. Chem. Soc. Rev., 2009, 38(1): 253-278.

[50] YANG Y, NIU S, HAN D, et al. Progress in developing metal oxide nanomaterials for photoelectrochemical water splitting. Adv. Energy Mater., 2017, 7(19): 1700555.

[51] QIU W T, HUANG Y C, WANG Z L, et al. Effective strategies towards high-performance photoanodes for photoelectrochemical water splitting. Acta Phys. Chim. Sin., 2017, 33(1): 80-102.

[52] CHEN Z B, JARAMILLO T F, DEUTSCH T G, et al. Accelerating materials development for photoelectrochemical hydrogen production: standards for methods, definitions, and reporting protocols. J. Mater. Res., 2010, 25(1): 3-16.

[53] DONG P, HOU G, XI X, et al. $\mathrm{WO}_{3}$-based photocatalysts: morphology control, activity enhancement and multifunctional applications. Environ. Sci.: Nano, 2017, 4(3): 539-557.

[54] ANIK M, CANSIZOGLU T. Dissolution kinetics of $\mathrm{WO}_{3}$ in acidic solutions. J. Appl. Electrochem., 2006, 36(5): 603-608.

[55] SEABOLD J A, CHOI K S. Effect of a cobalt-based oxygen evolution catalyst on the stability and the selectivity of photo-oxidation reactions of a $\mathrm{WO}_{3}$ photoanode. Chem. Mater., 2011, 23(5): 11051112.

[56] HUANG J, DING Y, LUO X, et al. Solvation effect promoted formation of $\mathrm{p}-\mathrm{n}$ junction between $\mathrm{WO}_{3}$ and $\mathrm{FeOOH}$ : a high performance photoanode for water oxidation. J. Catal., 2016, 333: 200-206.

[57] HUANG J, ZHANG Y, DING Y. Rationally designed/constructed $\mathrm{CoO}_{x} / \mathrm{WO}_{3}$ anode for efficient photoelectrochemical water oxidation. ACS Catal., 2017, 7(3): 1841-1845.

[58] LIU R, LIN Y, CHOU L Y, et al. Water splitting by tungsten oxide prepared by atomic layer deposition and decorated with an oxygenevolving catalyst. Angew. Chem. Int. Ed., 2011, 50(2): 499- 502.

[59] LIU Y, LI J, LI W, et al. Enhanced photoelectrochemical performance of $\mathrm{WO}_{3}$ film with $\mathrm{HfO}_{2}$ passivation layer. Int. J. Hydrogen Energy, 2015, 40(29): 8856-8863.

[60] SU J, FENG X, SLOPPY J D, et al. Vertically aligned $\mathrm{WO}_{3}$ nanowire arrays grown directly on transparent conducting oxide coated glass: synthesis and photoelectrochemical properties. Nano Lett., 2011, 11(1): 203-208.

[61] LI W, DA P, ZHANG Y, et al. $\mathrm{WO}_{3}$ nanoflakes for enhanced photoelectrochemical conversion. ACS Nano, 2014, 8(11): 11770 11777.

[62] ZHAO Z, BUTBUREE T, LYV M, et al. Etching treatment of vertical $\mathrm{WO}_{3}$ nanoplates as a photoanode for enhanced photoelectrochemical performance. RSC Adv., 2016, 6(72): 68204-68210.

[63] AMANO F, LI D, OHTANI B. Fabrication and photoelectrochemical property of tungsten (VI) oxide films with a flake-wall structure. Chem. Commun., 2010, 46(16): 2769-2771.
[64] YANG J, LI W Z, LI J, et al. Hydrothermal synthesis and photoelectrochemical properties of vertically aligned tungsten trioxide (hydrate) plate-like arrays fabricated directly on FTO substrates. $J$. Mater. Chem., 2012, 22(34): 17744-17752.

[65] KALANUR S S, HWANG Y J, CHAE S Y, et al. Facile growth of aligned $\mathrm{WO}_{3}$ nanorods on FTO substrate for enhanced photoanodic water oxidation activity. J. Mater. Chem. A, 2013, 1(10): 3479-3488.

[66] LIU Y, ZHAO L, SU J, et al. Fabrication and properties of a branched $\left(\mathrm{NH}_{4}\right)_{x} \mathrm{WO}_{3}$ nanowire array film and a porous $\mathrm{WO}_{3}$ nanorod array film. ACS Appl. Mater. Interfaces, 2015, 7(6): 3532-3538.

[67] WANG N, WANG D, LI M, et al. Photoelectrochemical water oxidation on photoanodes fabricated with hexagonal nanoflower and nanoblock $\mathrm{WO}_{3}$. Nanoscale, 2014, 6(4): 2061-2066.

[68] KAFIZAS A, FRANCÀS L, SOTELO-VAZQUEZ C, et al. Optimizing the activity of nanoneedle structured $\mathrm{WO}_{3}$ photoanodes for solar water splitting: direct synthesis via chemical vapor deposition. J. Phys. Chem. C, 2017, 121(11): 5983-5993.

[69] BISWAS S K, BAEG J O. A facile one-step synthesis of single crystalline hierarchical $\mathrm{WO}_{3}$ with enhanced activity for photoelectrochemical solar water oxidation. Int. J. Hydrogen Energy, 2013, 38(8): 3177-3188.

[70] XIE Y P, LIU G, YIN L C, et al. Crystal facet-dependent photocatalytic oxidation and reduction reactivity of monoclinic $\mathrm{WO}_{3}$ for solar energy conversion. J. Mater. Chem., 2012, 22(14): 67466751.

[71] ZHENG J Y, SONG G, HONG J, et al. Facile fabrication of $\mathrm{WO}_{3}$ nanoplates thin films with dominant crystal facet of (002) for water splitting. Cryst. Growth Des., 2014, 14(11): 6057-6066.

[72] ZHANG J J, ZHANG P, WANG $\mathrm{T}$, et al. Monoclinic $\mathrm{WO}_{3}$ nanomultilayers with preferentially exposed (002) facets for photoelectrochemical water splitting. Nano Energy, 2015, 11: 189195.

[73] WANG S C, CHEN H J, GAO G P, et al. Synergistic crystal facet engineering and structural control of $\mathrm{WO}_{3}$ films exhibiting unprecedented photoelectrochemical performance. Nano Energy, 2016, 24: 94-102.

[74] LIU X, WANG F, WANG Q. Nanostructure-based $\mathrm{WO}_{3}$ photoanodes for photoelectrochemical water splitting. Phys. Chem. Chem. Phys., 2012, 14(22): 7894-7911.

[75] SUN Y, MURPHY C J, REYES-GIL K R, et al. Photoelectrochemical and structural characterization of carbon-doped $\mathrm{WO}_{3}$ films prepared via spray pyrolysis. Int. J. Hydrogen Energy, 2009, 34(20): 8476-8484.

[76] MI Q, PING Y, LI Y, et al. Thermally stable $\mathrm{N}_{2}$-intercalated $\mathrm{WO}_{3}$ photoanodes for water oxidation. J. Am. Chem. Soc., 2012, 134(44): 18318-18324.

[77] COLE B, MARSEN B, MILLER E, et al. Evaluation of nitrogen doping of tungsten oxide for photoelectrochemical water splitting. J. Phys. Chem. C, 2008, 112(13): 5213-5220.

[78] LIU Y, LI J, LI W, et al. Enhancement of the photoelectrochemical performance of $\mathrm{WO}_{3}$ vertical arrays film for solar water splitting by gadolinium doping. J. Phys. Chem. C, 2015, 119(27): 14834-14842.

[79] LIU Q, LIU Y, LI C, et al. Hydrothermal Sm-doped tungsten oxide vertically plate-like array photoelectrode and its enhanced photoelectrocatalytic efficiency for degradation of organic dyes. $J$. Mater. Sci.: Mater. Electron., 2016, 28(5): 4004-4013.

[80] SARNOWSKA M, BIENKOWSKI K, BARCZUK P J, et al. Highly efficient and stable solar water splitting at $(\mathrm{Na}) \mathrm{WO}_{3}$ photoanodes in acidic electrolyte assisted by non-noble metal ox- 
oxygen evolution catalyst. Adv. Energy Mater., 2016, 6(14): 1600526.

[81] WANG G M, LING Y C, WANG H Y, et al. Hydrogen-treated $\mathrm{WO}_{3}$ nanoflakes show enhanced photostability. Energy Environ. Sci., 2012, 5(3): 6180-6187.

[82] ZHAO J, OLIDE E, OSTERLOH F E. Enhancing majority carrier transport in $\mathrm{WO}_{3}$ water oxidation photoanode via electrochemical doping. J. Electrochem. Soc., 2015, 162(1): H65-H71.

[83] MA M, ZHANG K, LI P, et al. Dual oxygen and tungsten vacancies on a $\mathrm{WO}_{3}$ photoanode for enhanced water oxidation. Angew. Chem., 2016, 128(39): 11998-12002.

[84] WANG F, DI VALENTIN C, PACCHIONI G. Doping of $\mathrm{WO}_{3}$ for photocatalytic water splitting: hints from density functional theory. J. Phys. Chem. C, 2012, 116(16): 8901-8909.

[85] WANG S, YUN J H, LUO B, et al. Recent progress on visible light responsive heterojunctions for photocatalytic applications. $J$. Mater. Sci. Technol., 2017, 33(1): 1-22.

[86] HOU Y, ZUO F, DAGG A P, et al. Branched $\mathrm{WO}_{3}$ nanosheet array with layered $\mathrm{C}_{3} \mathrm{~N}_{4}$ heterojunctions and $\mathrm{CoO}_{x}$ nanoparticles as a flexible photoanode for efficient photoelectrochemical water oxidation. Adv. Mater., 2014, 26(29): 5043-5049.

[87] HE H, BERGLUND S P, XIAO P, et al. Nanostructured $\mathrm{Bi}_{2} \mathrm{~S}_{3} / \mathrm{WO}_{3}$ heterojunction films exhibiting enhanced photoelectrochemical performance. J. Mater. Chem. A, 2013, 1(41): 12826-12834.

[88] ZHANG J, MA H, LIU Z. Highly efficient photocatalyst based on all oxides $\mathrm{WO}_{3} / \mathrm{Cu}_{2} \mathrm{O}$ heterojunction for photoelectrochemical water splitting. Appl. Catal., B, 2017, 201: 84-91.

[89] LI H, ZHAO F, ZHANG J, et al. A g- $\mathrm{C}_{3} \mathrm{~N}_{4} / \mathrm{WO}_{3}$ photoanode with exceptional ability for photoelectrochemical water splitting. Mater. Chem. Front., 2017, 1(2): 338-342.

[90] ZHANG J, LIU Z, LIU Z. Novel $\mathrm{WO}_{3} / \mathrm{Sb}_{2} \mathrm{~S}_{3}$ heterojunction photocatalyst based on $\mathrm{WO}_{3}$ of different morphologies for enhanced efficiency in photoelectrochemical water splitting. ACS Appl. Mater. Interfaces, 2016, 8(15): 9684-9691.

[91] ZHAO Z, BUTBUREE T, PEERAKIATKHAJOHN P, et al. Carbon quantum dots sensitized vertical $\mathrm{WO}_{3}$ nanoplates with enhanced photoelectrochemical properties. Chemistry Select, 2016, 1(11): 2772-2777.

[92] SOLARSKA R, KROLIKOWSKA A, AUGUSTYNSKI J. Silver nanoparticle induced photocurrent enhancement at $\mathrm{WO}_{3}$ photoanodes. Angew. Chem. Int. Ed., 2010, 49(43): 7980-7983.

[93] SHEN S H, LINDLEY S A, CHEN X Y, et al. Hematite heterostructures for photoelectrochemical water splitting: rational materials design and charge carrier dynamics. Energy Environ. Sci., 2016, 9(9): 2744-2775.

[94] HUANG Z Q, LIN Y J, XIANG X, et al. In situ probe of photocarrier dynamics in water-splitting hematite $\left(\alpha-\mathrm{Fe}_{2} \mathrm{O}_{3}\right)$ electrodes. Energy Environ. Sci., 2012, 5(10): 8923-8926.

[95] WHEELER D A, WANG G M, LING Y C, et al. Nanostructured hematite: synthesis, characterization, charge carrier dynamics, and photoelectrochemical properties. Energy Environ. Sci., 2012, 5(5): 6682-6702.

[96] CUMMINGS C Y, MARKEN F, PETER L M, et al. New insights into water splitting at mesoporous $\alpha-\mathrm{Fe}_{2} \mathrm{O}_{3}$ films: a study by modulated transmittance and impedance spectroscopies. J. Am. Chem. Soc., 2012, 134(2): 1228-1234.

[97] JUN H, IM B, KIM J Y, et al. Photoelectrochemical water splitting over ordered honeycomb hematite electrodes stabilized by alumina shielding. Energy Environ. Sci., 2012, 5(4): 6375-6382.

[98] BARROSO M, COWAN A J, PENDLEBURY S R, et al. The role of cobalt phosphate in enhancing the photocatalytic activity of
$\alpha-\mathrm{Fe}_{2} \mathrm{O}_{3}$ toward water oxidation. J. Am. Chem. Soc., 2011, 133(38): 14868-14871.

[99] QIU Y, LEUNG S F, ZHANG Q, et al. Efficient photoelectrochemical water splitting with ultrathin films of hematite on three-dimensional nanophotonic structures. Nano Lett., 2014, 14(4): 2123-2129.

[100] ZHANG P, WANG T, CHANG X, et al. Synergistic cocatalytic effect of carbon nanodots and $\mathrm{Co}_{3} \mathrm{O}_{4}$ nanoclusters for the photoelectrochemical water oxidation on hematite. Angew. Chem. Int. Ed., 2016, 55(19): 5851-5855.

[101] FECKL J M, DUNN H K, ZEHETMAIER P M, et al. Ultrasmall $\mathrm{CO}_{3} \mathrm{O}_{4}$ nanocrystals strongly enhance solar water splitting on mesoporous hematite. Advanced Materials Interfaces, 2015, 2(18): 1500358.

[102] KIM J Y, YOUN D H, KANG K, et al. Highly conformal deposition of an ultrathin $\mathrm{FeOOH}$ layer on a hematite nanostructure for efficient solar water splitting. Angew. Chem. Int. Ed., 2016, 55(36): 10854-10858.

[103] YU Q, MENG X G, WANG T, et al. Hematite films decorated with nanostructured ferric oxyhydroxide as photoanodes for efficient and stable photoelectrochemical water splitting. Adv. Funct. Mater., 2015, 25(18): 2686-2692.

[104] TAMirAT A G, SU W N, DUBALE A A, et al. Photoelectrochemical water splitting at low applied potential using a $\mathrm{NiOOH}$ coated codoped (Sn, $\mathrm{Zr}) \alpha-\mathrm{Fe}_{2} \mathrm{O}_{3}$ photoanode. J. Mater. Chem. A, 2015, 3(11): 5949-5961.

[105] CAI L, ZHAO J, LI H, et al. One-step hydrothermal deposition of Ni: FeOOH onto photoanodes for enhanced water oxidation. ACS Energy Letters, 2016, 1(3): 624-632.

[106] DU C, YANG X, MAYER M T, et al. Hematite-based water splitting with low turn-on voltages. Angew. Chem. Int. Ed., 2013, 52(48): 12692-12695.

[107] XU Y F, WANG X D, CHEN H Y, et al. Toward high performance photoelectrochemical water oxidation: combined effects of ultrafine cobalt iron oxide nanoparticle. Adv. Funct. Mater., 2016, 26(24): 4414-4421.

[108] CESAR I, KAY A, GONZALEZ MARTINEZ J A, et al. Translucent thin film $\mathrm{Fe}_{2} \mathrm{O}_{3}$ photoanodes for efficient water splitting by sunlight: nanostructure-directing effect of Si-doping. J. Am. Chem. Soc., 2006, 128(14): 4582-4583.

[109] CESAR I, SIVULA K, KAY A, et al. Influence of feature size, film thickness, and silicon doping on the performance of nanostructured hematite photoanodes for solar water splitting. J. Phys. Chem. C, 2009, 113(2): 772-782.

[110] ZHONG D K, SUN J, INUMARU H, et al. Solar water oxidation by composite catalyst $/ \alpha-\mathrm{Fe}_{2} \mathrm{O}_{3}$ photoanodes. J. Am. Chem. Soc., 2009, 131(17): 6086-6087.

[111] ZHONG D K, GAMELIN D R. Photoelectrochemical water oxidation by cobalt catalyst ("Co-Pi")/ $\alpha-\mathrm{Fe}_{2} \mathrm{O}_{3}$ composite photoanodes: oxygen evolution and resolution of a kinetic bottleneck. $J$. Am. Chem. Soc., 2010, 132(12): 4202-4207.

[112] ZHONG D K, CORNUZ M, SIVULA K, et al. Photo-assisted electrodeposition of cobalt-phosphate (Co-Pi) catalyst on hematite photoanodes for solar water oxidation. Energy Environ. Sci., 2011, 4(5): 1759-1764.

[113] TILLEY S D, CORNUZ M, SIVULA K, et al. Light-induced water splitting with hematite: improved nanostructure and iridium oxide catalysis. Angew. Chem., 2010, 122(36): 6549-6552.

[114] HAHN N T, MULLINS C B. Photoelectrochemical performance of nanostructured Ti- and Sn-doped $\alpha-\mathrm{Fe}_{2} \mathrm{O}_{3}$ photoanodes. Chem. Mater., 2010, 22(23): 6474-6482.

[115] KLEIMAN-SHWARSCTEIN A, HU Y S, FORMAN A J, et al. 
Electrodeposition of $\alpha-\mathrm{Fe}_{2} \mathrm{O}_{3}$ doped with $\mathrm{Mo}$ or $\mathrm{Cr}$ as photoanodes for photocatalytic water splitting. J. Phys. Chem. C, 2008, 112(40): 15900-15907.

[116] KLEIMAN-SHWARSCTEIN A, HUDA M N, WALSH A, et al. Electrodeposited aluminum-doped $\alpha-\mathrm{Fe}_{2} \mathrm{O}_{3}$ photoelectrodes: experiment and theory. Chem. Mater., 2010, 22(2): 510-517.

[117] KUMAR P, SHARMA P, SHRIVASTAV R, et al. Electrodeposited zirconium-doped $\alpha-\mathrm{Fe}_{2} \mathrm{O}_{3}$ thin film for photoelectrochemical water splitting. Int. J. Hydrogen Energy, 2011, 36(4): 2777-2784.

[118] FU Y, DONG C L, LEE W Y, et al. Nb-doped hematite nanorods for efficient solar water splitting: electronic structure evolution vs morphology alteration. ChemNanoMat, 2016, 2(7): 704-711.

[119] LING Y, WANG G, WHEELER D A, et al. Sn-doped hematite nanostructures for photoelectrochemical water splitting. Nano Lett., 2011, 11(5): 2119-2125.

[120] SIVULA K, ZBORIL R, LE FORMAL F, et al. Photoelectrochemical water splitting with mesoporous hematite prepared by a solution-based colloidal approach. J. Am. Chem. Soc., 2010, 132(21): 7436-7444.

[121] BRILLET J, GRATZEL M, SIVULA K. Decoupling feature size and functionality in solution-processed, porous hematite electrodes for solar water splitting. Nano Lett., 2010, 10(10): 4155-4160.

[122] LI M, YANG Y, LING Y, et al. Morphology and doping engineering of Sn-doped hematite nanowire photoanodes. Nano Lett., 2017, 17(4): 2490-2495

[123] LI C, LI A, LUO Z, et al. Surviving high-temperature calcination: $\mathrm{ZrO}_{2}$-induced hematite nanotubes for photoelectrochemical water oxidation. Angew. Chem. Int. Ed., 2017, 56(15): 4150-4155.

[124] ANNAMALAI A, SUBRAMANIAN A, KANG U, et al. Activation of hematite photoanodes for solar water splitting: effect of FTO deformation. J. Phys. Chem. C, 2015, 119(7): 3810-3817.

[125] FRANKING R, LI L, LUKOWSKI M A, et al. Facile post-growth doping of nanostructured hematite photoanodes for enhanced photoelectrochemical water oxidation. Energy Environ. Sci., 2013, 6(2): 500-512.

[126] WANG D, CHANG G, ZHANG Y, et al. Hierarchical three-dimensional branched hematite nanorod arrays with enhanced mid-visible light absorption for high-efficiency photoelectrochemical water splitting. Nanoscale, 2016, 8(25): 12697-12701.

[127] LIU J, CAI Y Y, TIAN Z F, et al. Highly oriented Ge-doped hematite nanosheet arrays for photoelectrochemical water oxidation. Nano Energy, 2014, 9: 282-290.

[128] KIM J Y, MAGESH G, YOUN D H, et al. Single-crystalline, wormlike hematite photoanodes for efficient solar water splitting. Sci. Rep., 2013, 3: 2681.

[129] GUO X L, WANG L L, TAN Y W. Hematite nanorods Co-doped with Ru cations with different valence states as high performance photoanodes for water splitting. Nano Energy, 2015, 16: 320-328.

[130] PEERAKIATKHAJOHN P, YUN J H, CHEN H, et al. Stable hematite nanosheet photoanodes for enhanced photoelectrochemical water splitting. Adv. Mater., 2016, 28(30): 6405-6410.

[131] KANG J S, NOH Y, KIM J, et al. Iron oxide photoelectrode with multidimensional architecture for highly efficient photoelectrochemical water splitting. Angew. Chem. Int. Ed., 2017, 56(23): 6583-6588.

[132] HOU Y, ZUO F, DAGG A, et al. A three-dimensional branched cobalt-doped $\alpha-\mathrm{Fe}_{2} \mathrm{O}_{3}$ nanorod/ $\mathrm{MgFe}_{2} \mathrm{O}_{4}$ heterojunction array as a flexible photoanode for efficient photoelectrochemical water oxidation. Angew. Chem., 2013, 125(4): 1286-1290.

[133] LIN Y, ZHOU S, SHEEHAN S W, et al. Nanonet-based hematite heteronanostructures for efficient solar water splitting. J. Am.
Chem. Soc., 2011, 133(8): 2398-2401.

[134] SIVULA K, FORMAL F L, GRÄTZEL M. $\mathrm{WO}_{3}-\mathrm{Fe}_{2} \mathrm{O}_{3}$ photoanodes for water splitting: a host scaffold, guest absorber approach. Chem. Mater., 2009, 21(13): 2862-2867.

[135] HOU Y, ZUO F, DAGG A, et al. Visible light-driven $\alpha-\mathrm{Fe}_{2} \mathrm{O}_{3}$ nanorod/graphene/ $\mathrm{BiV}_{1-x} \mathrm{Mo}_{x} \mathrm{O}_{4}$ core/shell heterojunction array for efficient photoelectrochemical water splitting. Nano Lett., 2012, 12(12): 6464-6473.

[136] XU Y F, RAO H S, CHEN B X, et al. Achieving highly efficient photoelectrochemical water oxidation with a $\mathrm{TiCl}_{4}$ treated $3 \mathrm{D}$ antimony-doped $\mathrm{SnO}_{2}$ macropore/branched $\alpha-\mathrm{Fe}_{2} \mathrm{O}_{3}$ nanorod heterojunction photoanode. Adv. Sci., 2015, 2(7): 1500049.

[137] MIAO C, JI S, XU G, et al. Micro-nano-structured $\mathrm{Fe}_{2} \mathrm{O}_{3}$ : $\mathrm{Ti} / \mathrm{ZnFe}_{2} \mathrm{O}_{4}$ heterojunction films for water oxidation. ACS Appl. Mater. Interfaces, 2012, 4(8): 4428-4433.

[138] AHMED M G, KANDIEL T A, AHMED A Y, et al. Enhanced photoelectrochemical water oxidation on nanostructured hematite photoanodes via $\mathrm{p}-\mathrm{CaFe}_{2} \mathrm{O}_{4} / \mathrm{n}-\mathrm{Fe}_{2} \mathrm{O}_{3}$ heterojunction formation. $J$. Phys. Chem. C, 2015, 119(11): 5864-5871.

[139] DENG J, LV X, LIU J, et al. Thin-layer $\mathrm{Fe}_{2} \mathrm{TiO}_{5}$ on hematite for efficient solar water oxidation. ACS Nano, 2015, 9(5): 5348-5356.

[140] BASSI P S, ANTONY R P, BOIX P P, et al. Crystalline $\mathrm{Fe}_{2} \mathrm{O}_{3} / \mathrm{Fe}_{2} \mathrm{TiO}_{5}$ heterojunction nanorods with efficient charge separation and hole injection as photoanode for solar water oxidation. Nano Energy, 2016, 22: 310-318.

[141] LI C, WANG T, LUO Z, et al. Enhanced charge separation through ALD-modified $\mathrm{Fe}_{2} \mathrm{O}_{3} / \mathrm{Fe}_{2} \mathrm{TiO}_{5}$ nanorod heterojunction for photoelectrochemical water oxidation. Small, 2016, 12(25): 34153422.

[142] PARK Y, MCDONALD K J, CHOI K S. Progress in bismuth vanadate photoanodes for use in solar water oxidation. Chem. Soc. Rev., 2013, 42(6): 2321-2337.

[143] HUANG Z F, PAN L, ZOU J J, et al. Nanostructured bismuth vanadate-based materials for solar-energy-driven water oxidation: a review on recent progress. Nanoscale, 2014, 6(23): 14044 14063.

[144] ABDI F F, SAVENIJE T J, MAY M M, et al. The origin of slow carrier transport in $\mathrm{BiVO}_{4}$ thin film photoanodes: a time-resolved microwave conductivity study. J. Phys. Chem. Lett., 2013, 4(16): 2752-2757.

[145] TOLOD K, HERNÁNDEZ S, RUSSO N. Recent advances in the $\mathrm{BiVO}_{4}$ photocatalyst for sun-driven water oxidation: top-performing photoanodes and scale-up challenges. Catalysts, 2017, 7(1): 13.

[146] BERGLUND S P, RETTIE A J, HOANG S, et al. Incorporation of Mo and $\mathrm{W}$ into nanostructured $\mathrm{BiVO}_{4}$ films for efficient photoelectrochemical water oxidation. Phys. Chem. Chem. Phys., 2012, 14(19): 7065-7075.

[147] ABDI F F, HAN L, SMETS A H, et al. Efficient solar water splitting by enhanced charge separation in a bismuth vanadate-silicon tandem photoelectrode. Nat. Commun., 2013, 4: 2195.

[148] WANG G, LING Y, LU X, et al. Computational and photoelectrochemical study of hydrogenated bismuth vanadate. J. Phys. Chem. C, 2013, 117(21): 10957-10964.

[149] QIN D D, WANG T, SONG Y M, et al. Reduced monoclinic $\mathrm{BiVO}_{4}$ for improved photoelectrochemical oxidation of water under visible light. Dalton Trans., 2014, 43(21): 7691-7694.

[150] WANG G, YANG Y, LING Y, et al. An electrochemical method to enhance the performance of metal oxides for photoelectrochemical water oxidation. J. Mater. Chem. A, 2016, 4(8): 2849-2855.

[151] WANG S, CHEN P, YUN J H, et al. An electrochemically treated $\mathrm{BiVO}_{4}$ photoanode for efficient photoelectrochemical water splitting. Angew. Chem. Int. Ed., 2017, 56(29): 8500-8504. 
[152] BU Y Y, TIAN J, CHEN Z W, et al. Optimization of the photo-electrochemical performance of Mo-doped $\mathrm{BiVO}_{4}$ photoanode by controlling the metal-oxygen bond state on (020) facet. Advanced Materials Interfaces, 2017, 4(10): 1601235.

[153] KIM T W, CHOI K S. Nanoporous $\mathrm{BiVO}_{4}$ photoanodes with dual-layer oxygen evolution catalysts for solar water splitting. Science, 2014, 343(6174): 990-994.

[154] KIM T W, PING Y, GALLI G A, et al. Simultaneous enhancements in photon absorption and charge transport of bismuth vanadate photoanodes for solar water splitting. Nat. Commun., 2015, 6: 8769 .

[155] KUANG Y, JIA Q, NISHIYAMA H, et al. A front-illuminated nanostructured transparent $\mathrm{BiVO}_{4}$ photoanode for $>2 \%$ efficient water splitting. Adv. Energy Mater., 2016, 6(2): 1501645.

[156] WANG Y, LI F, ZHOU X, et al. Highly efficient photoelectrochemical water splitting with an immobilized molecular $\mathrm{Co}_{4} \mathrm{O}_{4}$ cubane catalyst. Angew. Chem. Int. Ed., 2017, 56(24): 6911-6915.

[157] YE K-H, WANG Z, GU J, et al. Carbon quantum dots as a visible light sensitizer to significantly increase the solar water splitting performance of bismuth vanadate photoanodes. Energy Environ. Sci., 2017, 10(3): 772-779.

[158] ZHONG M, HISATOMI T, MINEGISHI T, et al. Bulky crystalline $\mathrm{BiVO}_{4}$ thin films for efficient solar water splitting. J. Mater. Chem. A, 2016, 4(25): 9858-9864.

[159] HONG S J, LEE S, JANG J S, et al. Heterojunction $\mathrm{BiVO}_{4} / \mathrm{WO}_{3}$ electrodes for enhanced photoactivity of water oxidation. Energy Environ. Sci., 2011, 4(5): 1781-1787.

[160] SU J, GUO L, BAO N, et al. Nanostructured $\mathrm{WO}_{3} / \mathrm{BiVO}_{4}$ heterojunction films for efficient photoelectrochemical water splitting. Nano Lett., 2011, 11(5): 1928-1933.

[161] PIHOSH Y, TURKEVYCH I, MAWATARI K, et al. Nanostructured $\mathrm{WO}_{3} / \mathrm{BiVO}_{4}$ photoanodes for efficient photoelectrochemical water splitting. Small, 2014, 10(18): 3692-3699.

[162] RAO P M, CAI L, LIU C, et al. Simultaneously efficient light absorption and charge separation in $\mathrm{WO}_{3} / \mathrm{BiVO}_{4}$ core/shell nanowire photoanode for photoelectrochemical water oxidation. Nano Lett., 2014, 14(2): 1099-1105.

[163] SHI X, CHOI I Y, ZHANG K, et al. Efficient photoelectrochemical hydrogen production from bismuth vanadate-decorated tungsten trioxide helix nanostructures. Nat. Commun., 2014, 5: 4775.

[164] XIA L, BAI J, LI J, et al. A highly efficient $\mathrm{BiVO}_{4} / \mathrm{WO}_{3} / \mathrm{W}$ heterojunction photoanode for visible-light responsive dual photoelectrode photocatalytic fuel cell. Appl. Catal., B, 2016, 183: 224-230.

[165] LEE M G, KIM D H, SOHN W, et al. Conformally coated $\mathrm{BiVO}_{4}$ nanodots on porosity-controlled $\mathrm{WO}_{3}$ nanorods as highly efficient type II heterojunction photoanodes for water oxidation. Nano Energy, 2016, 28: 250-260.

[166] PIHOSH Y, TURKEVYCH I, MAWATARI K, et al. Photocatalytic generation of hydrogen by core-shell $\mathrm{WO}_{3} / \mathrm{BiVO}_{4}$ nanorods with ultimate water splitting efficiency. Sci. Rep., 2015, 5: 11141.

[167] SAITO R, MISEKI Y, SAYAMA K. Highly efficient photoelectrochemical water splitting using a thin film photoanode of $\mathrm{BiVO}_{4} / \mathrm{SnO}_{2} / \mathrm{WO}_{3}$ multi-composite in a carbonate electrolyte. Chem. Commun., 2012, 48(32): 3833-3835.

[168] BAEK J H, KIM B J, HAN G S, et al. $\mathrm{BiVO}_{4} / \mathrm{WO}_{3} / \mathrm{SnO}_{2}$ doubleheterojunction photoanode with enhanced charge separation and visible-transparency for bias-free solar water-splitting with a perovskite solar cell. ACS Appl. Mater. Interfaces, 2017, 9(2): 1479-1487.

[169] CHENG B Y, YANG J S, CHO H W, et al. Fabrication of an effi- cient $\mathrm{BiVO}_{4}-\mathrm{TiO}_{2}$ heterojunction photoanode for photoelectrochemical water oxidation. ACS Appl. Mater. Interfaces, 2016, 8(31): 20032-20039.

[170] AN X, LI T, WEN B, et al. New insights into defect-mediated heterostructures for photoelectrochemical water splitting. Adv. Energy Mater., 2016, 6(8): 1502268.

[171] HESS L H, COOPER J K, LOIUDICE A, et al. Probing interfacial energetics and charge transfer kinetics in semiconductor nanocomposites: new insights into heterostructured $\mathrm{TiO}_{2} / \mathrm{BiVO}_{4}$ photoanodes. Nano Energy, 2017, 34: 375-384.

[172] ZHOU L, ZHAO C, GIRI B, et al. High light absorption and charge separation efficiency at low applied voltage from Sb-doped $\mathrm{SnO}_{2} / \mathrm{BiVO}_{4}$ core/shell nanorod-array photoanodes. Nano Lett., 2016, 16(6): 3463-3474.

[173] RESASCO J, ZHANG H, KORNIENKO N, et al. $\mathrm{TiO}_{2} / \mathrm{BiVO}_{4}$ nanowire heterostructure photoanodes based on type II band alignment. ACS Cent Sci, 2016, 2(2): 80-88.

[174] YE K H, CHAI Z S, GU J W, et al. BiOI-BiVO 4 photoanodes with significantly improved solar water splitting capability: p-n junction to expand solar adsorption range and facilitate charge carrier dynamics. Nano Energy, 2015, 18: 222-231.

[175] YANG J S, WU J J. Low-potential driven fully-depleted $\mathrm{BiVO}_{4} / \mathrm{ZnO}$ heterojunction nanodendrite array photoanodes for photoelectrochemical water splitting. Nano Energy, 2017, 32: 232-240.

[176] MONIZ S J A, ZHU J, TANG J. 1D Co-Pi modified $\mathrm{BiVO}_{4} / \mathrm{ZnO}$ junction cascade for efficient photoelectrochemical water cleavage. Adv. Energy Mater., 2014, 4(10): 1301590.

[177] SU J Y, BAI Z W, HUANG B L, et al. Unique three dimensional architecture using a metal-free semiconductor cross-linked bismuth vanadate for efficient photoelectrochemical water oxidation. Nano Energy, 2016, 24: 148-157.

[178] KIM E S, KANG H J, MAGESH G, et al. Improved photoelectrochemical activity of $\mathrm{CaFe}_{2} \mathrm{O}_{4} / \mathrm{BiVO}_{4}$ heterojunction photoanode by reduced surface recombination in solar water oxidation. ACS Appl. Mater. Interfaces, 2014, 6(20): 17762-17769.

[179] CHANG X, WANG T, ZHANG P, et al. Enhanced surface reaction kinetics and charge separation of $\mathrm{p}$-n heterojunction $\mathrm{Co}_{3} \mathrm{O}_{4} / \mathrm{BiVO}_{4}$ photoanodes. J. Am. Chem. Soc., 2015, 137(26): 8356-8359.

[180] XI G, YE J. Synthesis of bismuth vanadate nanoplates with exposed $\{001\}$ facets and enhanced visible-light photocatalytic properties. Chem. Commun., 2010, 46(11): 1893-1895.

[181] WANG D, JIANG H, ZONG X, et al. Crystal facet dependence of water oxidation on $\mathrm{BiVO}_{4}$ sheets under visible light irradiation. Chem. Eur. J., 2011, 17(4): 1275-1282.

[182] KIM C W, SON Y S, KANG M J, et al. (040)-crystal facet engineering of $\mathrm{BiVO}_{4}$ plate photoanodes for solar fuel production. Adv. Energy Mater., 2016, 6(4): 1501754.

[183] ZHU Y K, REN J, YANG X F, et al. Interface engineering of 3D $\mathrm{BiVO}_{4} / \mathrm{Fe}$-based layered double hydroxide core/shell nanostructures for boosting photoelectrochemical water oxidation. J. Mater. Chem. A, 2017, 5(20): 9952-9959.

[184] LIU G, YANG H G, PAN J, et al. Titanium dioxide crystals with tailored facets. Chem. Rev., 2014, 114(19): 9559-9612.

[185] LI R, ZHANG F, WANG D, et al. Spatial separation of photogenerated electrons and holes among $\{010\}$ and $\{110\}$ crystal facets of $\mathrm{BiVO}_{4}$. Nat. Commun., 2013, 4: 1432.

[186] LI R G, HAN H X, ZHANG F X, et al. Highly efficient photocatalysts constructed by rational assembly of dual-cocatalysts separately on different facets of $\mathrm{BiVO}_{4}$. Energy Environ. Sci., 
2014, 7(4): 1369-1376.

[187] CHEN S, WANG L W. Thermodynamic oxidation and reduction potentials of photocatalytic semiconductors in aqueous solution. Chem. Mater., 2012, 24(18): 3659-3666.

[188] LICHTERMAN M F, SHANER M R, HANDLER S G, et al. Enhanced stability and activity for water oxidation in alkaline media with bismuth vanadate photoelectrodes modified with a cobalt oxide catalytic layer produced by atomic layer deposition. J. Phys. Chem. Lett., 2013, 4(23): 4188-4191.

[189] MCDOWELL M T, LICHTERMAN M F, SPURGEON J M, et al. Improved stability of polycrystalline bismuth vanadate photoanodes by use of dual-layer thin $\mathrm{TiO}_{2} / \mathrm{Ni}$ coatings. J. Phys. Chem. C, 2014, 118(34): 19618-19624.

[190] KIM T W, CHOI K S. Improving stability and photoelectrochemical performance of $\mathrm{BiVO}_{4}$ photoanodes in basic media by adding a $\mathrm{ZnFe}_{2} \mathrm{O}_{4}$ layer. $J$ Phys Chem Lett, 2016, 7(3): 447-451.

[191] TOMA F M, COOPER J K, KUNZELMANN V, et al. Mechanistic insights into chemical and photochemical transformations of bismuth vanadate photoanodes. Nat. Commun., 2016, 7: 12012.

[192] XIE J, GUO C, YANG P, et al. Bi-functional ferroelectric $\mathrm{BiFeO}_{3}$ passivated $\mathrm{BiVO}_{4}$ photoanode for efficient and stable solar water oxidation. Nano Energy, 2017, 31: 28-36.

[193] LUO W J, YANG Z S, LI Z S, et al. Solar hydrogen generation from seawater with a modified $\mathrm{BiVO}_{4}$ photoanode. Energy Environ. Sci., 2011, 4(10): 4046-4051.

[194] PILLI S K, FURTAK T E, BROWN L D, et al. Cobalt-phosphate (Co-Pi) catalyst modified Mo-doped $\mathrm{BiVO}_{4}$ photoelectrodes for solar water oxidation. Energy Environ. Sci., 2011, 4(12): 5028-5034.

[195] ZHONG D K, CHOI S, GAMELIN D R. Near-complete suppression of surface recombination in solar photoelectrolysis by "Co-Pi" catalyst-modified W: $\mathrm{BiVO}_{4}$. J. Am. Chem. Soc., 2011, 133(45): 18370-18377.

[196] KUANG Y, JIA Q, MA G, et al. Ultrastable low-bias water splitting photoanodes via photocorrosion inhibition and in situ catalyst regeneration. Nature Energy, 2016, 2(1): 16191.

[197] ZHANG K, MA M, LI P, et al. Water splitting progress in tandem devices: moving photolysis beyond electrolysis. Adv. Energy Mater., 2016, 6(15): 1600602.

[198] PEERAKIATKHAJOHN P, YUN J H, WANG S C, et al. Review of recent progress in unassisted photoelectrochemical water splitting: from material modification to configuration design. J. Photonics Energy, 2017, 7(1): 012006.

[199] BORNOZ P, ABDI F F, TILLEY S D, et al. A bismuth vanadate-cuprous oxide tandem cell for overall solar water splitting. J. Phys. Chem. C, 2014, 118(30): 16959-16966.

[200] JIANG F, GUNAWAN, HARADA $\mathrm{T}$, et al. $\mathrm{Pt} / \mathrm{In}_{2} \mathrm{~S}_{3} / \mathrm{CdS} /$ $\mathrm{Cu}_{2} \mathrm{ZnSnS}_{4}$ thin film as an efficient and stable photocathode for water reduction under sunlight radiation. J. Am. Chem. Soc., 2015, 137(42): 13691-13697.

[201] LIU B, WU C H, MIAO J, et al. All inorganic semiconductor nanowire mesh for direct solar water splitting. ACS Nano, 2014, 8(11): 11739-11744.

[202] JANG J W, DU C, YE Y, et al. Enabling unassisted solar water splitting by iron oxide and silicon. Nat. Commun., 2015, 6: 7447.

[203] HU S, XIANG C X, HAUSSENER S, et al. An analysis of the optimal band gaps of light absorbers in integrated tandem photoelectrochemical water-splitting systems. Energy Environ. Sci., 2013, 6(10): 2984-2993.

[204] REECE S Y, HAMEL J A, SUNG K, et al. Wireless solar water splitting using silicon-based semiconductors and earth-abundant catalysts. Science, 2011, 334(6056): 645-648.

[205] KHASELEV O, TURNER J A. A monolithic photovoltaic-photoe- lectrochemical device for hydrogen production via water splitting. Science, 1998, 280(5362): 425-427.

[206] LICHT S, WANG B, MUKERJI S, et al. Efficient solar water splitting, exemplified by $\mathrm{RuO}_{2}$-catalyzed AlGaAs/Si photoelectrolysis. J. Phys. Chem. B, 2000, 104(38): 8920-8924.

[207] BRILLET J, YUM J H, CORNUZ M, et al. Highly efficient water splitting by a dual-absorber tandem cell. Nat. Photonics, 2012, 6(12): 824-828.

[208] SHI X J, ZHANG K, SHIN K, et al. Unassisted photoelectrochemical water splitting beyond $5.7 \%$ solar-to-hydrogen conversion efficiency by a wireless monolithic photoanode/dye-sensitised solar cell tandem device. Nano Energy, 2015, 13: 182-191.

[209] SHI X, JEONG H, OH S J, et al. Unassisted photoelectrochemical water splitting exceeding $7 \%$ solar-to-hydrogen conversion efficiency using photon recycling. Nat. Commun., 2016, 7: 11943.

[210] DING C, QIN W, WANG N, et al. Solar-to-hydrogen efficiency exceeding $2.5 \%$ achieved for overall water splitting with an all earth-abundant dual-photoelectrode. Phys. Chem. Chem. Phys., 2014, 16(29): 15608-15614.

[211] KIM J H, JANG J W, JO Y H, et al. Hetero-type dual photoanodes for unbiased solar water splitting with extended light harvesting. Nat. Commun., 2016, 7: 13380.

[212] CHEN Y S, MANSER J S, KAMAT P V. All solution-processed lead halide perovskite- $\mathrm{BiVO}_{4}$ tandem assembly for photolytic solar fuels production. J. Am. Chem. Soc., 2015, 137(2): 974-981.

[213] QIU Y, LIU W, CHEN W, et al. Efficient solar-driven water splitting by nanocone $\mathrm{BiVO}_{4}$-perovskite tandem cells. Sci. Adv., 2016, 2(6): e1501764-1-9.

[214] KIM J H, JO Y, KIM J H, et al. Wireless solar water splitting device with robust cobalt-catalyzed, dual-doped $\mathrm{BiVO}_{4}$ photoanode and perovskite solar cell in tandem: a dual absorber artificial leaf. ACS Nano, 2015, 9(12): 11820-11829.

[215] JIA J, SEITZ L C, BENCK J D, et al. Solar water splitting by photovoltaic-electrolysis with a solar-to-hydrogen efficiency over 30\%. Nat. Commun., 2016, 7: 13237.

[216] LHERMITTE C R, BARTLETT B M. Advancing the chemistry of $\mathrm{CuWO}_{4}$ for photoelectrochemical water oxidation. Acc. Chem. Res., 2016, 49(6): 1121-1129.

[217] KANG D, PARK Y, HILL J C, et al. Preparation of Bi-based ternary oxide photoanodes $\mathrm{BiVO}_{4}, \mathrm{Bi}_{2} \mathrm{WO}_{6}$, and $\mathrm{Bi}_{2} \mathrm{Mo}_{3} \mathrm{O}_{12}$ using dendritic Bi metal electrodes. J. Phys. Chem. Lett., 2014, 5(17): 2994-2999.

[218] LIU Q, HE J, YAO T, et al. Aligned $\mathrm{Fe}_{2} \mathrm{TiO}_{5}$-containing nanotube arrays with low onset potential for visible-light water oxidation. Nat. Commun., 2014, 5: 5122.

[219] GUO W, CHEMELEWSKI W D, MABAYOJE O, et al. Synthesis and characterization of $\mathrm{CuV}_{2} \mathrm{O}_{6}$ and $\mathrm{Cu}_{2} \mathrm{~V}_{2} \mathrm{O}_{7}$ : two photoanode candidates for photoelectrochemical water oxidation. J. Phys. Chem. C, 2015, 119(49): 27220-27227.

[220] KIM M W, JOSHI B, YOON H, et al. Electrosprayed copper hexaoxodivanadate $\left(\mathrm{CuV}_{2} \mathrm{O}_{6}\right)$ and pyrovanadate $\left(\mathrm{Cu}_{2} \mathrm{~V}_{2} \mathrm{O}_{7}\right)$ photoanodes for efficient solar water splitting. J. Alloys Compd., 2017, 708: 444-450.

[221] SEABOLD J A, NEALE N R. All first row transition metal oxide photoanode for water splitting based on $\mathrm{Cu}_{3} \mathrm{~V}_{2} \mathrm{O}_{8}$. Chem. Mater., 2015, 27(3): 1005-1013

[222] WANG W, ZHANG Y J, WANG L, et al. Facile synthesis of $\mathrm{Fe}^{3+} / \mathrm{Fe}^{2+}$ self-doped nanoporous $\mathrm{FeVO}_{4}$ photoanodes for efficient solar water splitting. J. Mater. Chem. A, 2017, 5(6): 2478-2482.

[223] BISWAS S K, BAEG J O. Enhanced photoactivity of visible light responsive $\mathrm{W}$ incorporated $\mathrm{FeVO}_{4}$ photoanode for solar water splitting. Int. J. Hydrogen Energy, 2013, 38(34): 14451-14457. 


\title{
光电催化分解水用可见光响应型氧化物 光阳极的改性研究进展
}

\author{
王松灿，汤枫秋，王连洲 \\ (昆士兰大学 化工学院, 澳大利亚 4072)
}

\begin{abstract}
摘 要: 光电催化分解水是绿色制氢的重要途径之一。由于水氧化反应在热力学和动力学上极难发生, 因而制备高 效光阳极成为光电催化分解水的瓶颈问题。为满足未来商业化应用需求(太阳能制氢转换效率>10\%), 研制高效光 阳极成为亟待解决的关键难题。研究表明, 具有价格低廉、吸光性良好、毒性小且光电化学稳定性高等突出优点的 可见光响应型氧化物: $\mathrm{WO}_{3} 、 \alpha-\mathrm{Fe}_{2} \mathrm{O}_{3}$ 和 $\mathrm{BiVO}_{4}$, 是目前光电催化分解水用光阳极的理想材料。在过去几十年里, 围 绕该类氧化物光阳极的研究已取得显著成果。本文重点论述了高效光电催化分解水制氢用 $\mathrm{WO}_{3} 、 \alpha-\mathrm{Fe}_{2} \mathrm{O}_{3}$ 和 $\mathrm{BiVO}_{4}$ 光阳极改性的研究进展。另外, 文中简述了此类可见光响应型氧化物光阳极在无偏压光电催化分解水中的研究现状, 并提出其存在的问题及未来发展方向。
\end{abstract}

关 键 词: 太阳能转换; 半导体氧化物; 光阳极; 光电催化分解水; 太阳能制氢

中图分类号: TQ174 文献标识码: A

\section{我与严东生先生}

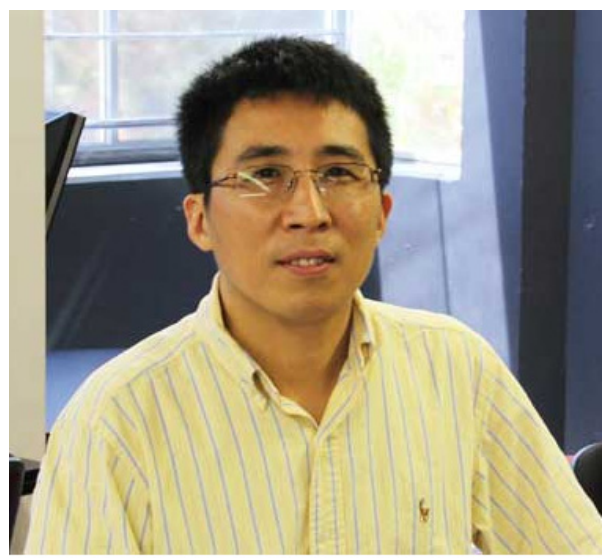

严东生先生 2016 年 9 月 18 日驾鹤西去已近一年，每每回想起 20 年前在中国科学院上海硅酸盐研究所先生门下求学读博的点点滴 滴, 仍忍不住唏嘘感怀。先生儒雅、博学、坦诚的人格鬼力和治学 严谨的做事风格至今深深地影响着我的一言一行。

严先生是我们国家材料科学领域泰斗级的科学家，同时也是科 学院的领导, 日常事务繁忙, 但有幸成为先生的学生, 总能得到先 生经常性的教诲。严先生时虽年近 8 旬, 但让我记忆犹新的是, 他 总是关注每位学生的研究方向, 询问研究进展情况, 讲述世界最新 前沿, 启迪创新思维, 特别对研究思路的点拨总能高屋建瓴、画龙 点睛。每当我们研究遇到瓶颈时, 先生总会耐心地了解实验过程, 与我们深入分析问题症结, 寻求解决方法。每当论文成稿送先生审 阅时, 先生总会反复推敲, 梳理论点论据。先生修改学生论文字㽎句酌, 对英文的语法、用词都会做非常 详尽的批改, 学生在国际期刊上发表的每一篇论文, 都凝聚着先生无数的心血。

严先生不仅在学术上给予我们指导, 而且在各方面对学生进行历练和支持。他经常创造机会让学生参 加各类国际学术会议, 开拓学术视野, 结识国际同行, 提升综合能力。记得我 1998 年第一次参加在北京举 行的一个国际会议作口头报告, 先生专门到会场支持, 因当时英语沟通能力有限, 先生还帮我回答了一个 问题。仅此一例, 先生对学生的拳拳爱惜之意已一望而知。

先生离开我们虽近一年, 但始终觉得先生没有离开, 他如家父般关怀的话语, 时常在耳边回响。有幸 师从先生三年, 受教终生。每当我科研上有进展时, 总想与先生分享, 也仿佛总能看到先生那慈眉善目的 容颜。今日执笔追思先生，千言万语汇成一句话：此生有幸，与师相逢！ 